\title{
molecules
}

ISSN 1420-3049

Article

www.mdpi.com/journal/molecules

\section{$t$-Bu $\mathrm{B}_{2} \mathrm{SiF}$-Derivatized $\mathrm{D}_{2}$-Receptor Ligands: The First SiFA-Containing Small Molecule Radiotracers for Target-Specific PET-Imaging}

Ljuba Iovkova-Berends ${ }^{1}$, Carmen Wängler ${ }^{2}$, Thomas Zöller ${ }^{1}$, Georg Höfner ${ }^{3}$, Klaus Theodor Wanner ${ }^{3}$, Christian Rensch ${ }^{4}$, Peter Bartenstein ${ }^{2}$, Alexey Kostikov ${ }^{5}$, Ralf Schirrmacher ${ }^{5}$, Klaus Jurkschat ${ }^{1, *}$ and Björn Wängler ${ }^{2, *}$

1 Department of Inorganic Chemistry II, Faculty of Chemistry, TU Dortmund, Otto-Hahn-Str. 6, 44221 Dortmund, Germany

2 Department of Nuclear Medicine, Ludwig-Maximilians-University, Marchioninistr. 15, 81377 Munich, Germany

3 Department of Pharmacy, Center for Drug Research, Ludwig-Maximilians-University, Butenandtstr. 7, 81377 Munich, Germany

4 GE Global Research, 85748 Garching, Germany

5 McConnell Brain Imaging Centre, Montreal Neurological Institute, McGill University, 3801 University St., Montreal H3A 2B4, QC, Canada

* Authors to whom correspondence should be addressed;

E-Mails: klaus.jurkschat@uni-dortmund.de (K.J.); bjoern.waengler@med.uni-muenchen.de (B.W.); Tel.: +49-231-755-3800 (K.J.); +49-89-7095-7543 (B.W.); Fax: +49-231-755-5048 (K.J.); +49-89-7095-4648 (B.W.).

Received: 28 July 2011; in revised form: 19 August 2011 / Accepted: 31 August 2011 /

Published: 2 September 2011

Abstract: The synthesis, radiolabeling and in vitro evaluation of new silicon-fluoride acceptor (SiFA) derivatized $\mathrm{D}_{2}$-receptor ligands is reported. The SiFA-technology simplifies the introduction of fluorine-18 into target specific biomolecules for PositronEmission-Tomography (PET). However, one of the remaining challenges, especially for small molecules such as receptor-ligands, is the bulkiness of the SiFA-moiety. We therefore synthesized four Fallypride SiFA-conjugates derivatized either directly at the benzoic acid ring system (SiFA-DMFP, SiFA-FP, SiFA-DDMFP) or at the butyl-side chain (SiFA-M-FP) and tested their receptor affinities. We found $\mathrm{D}_{2}$-receptor affinities for all compounds in the nanomolar range $\left(K_{\mathrm{i}(\mathrm{SiFA}-\mathrm{DMFP})}=13.6 \mathrm{nM}, K_{\mathrm{i}(\mathrm{SiFA}-\mathrm{FP})}=33.0 \mathrm{nM}\right.$, 
$K_{\mathrm{i}(\mathrm{SiFA}-\mathrm{DDMFP})}=62.7 \mathrm{nM}$ and $\left.K_{\mathrm{i}(\mathrm{SiFA}-\mathrm{M}-\mathrm{FP})}=4.21 \mathrm{nM}\right)$. The radiofluorination showed highest yields when $10 \mathrm{nmol}$ of the precursors were reacted with $\left[{ }^{18} \mathrm{~F}\right]$ fluoride $/ \mathrm{TBAHCO}_{3}$ in acetonitrile. After a reversed phased cartridge purification the desired products could be isolated as an injectable solution after only $10 \mathrm{~min}$ synthesis time with radiochemical yields (RCY) of more than $40 \%$ in the case of SiFA-DMFP resulting in specific activities $>41 \mathrm{GBq} / \mu \mathrm{mol}(>1,100 \mathrm{Ci} / \mathrm{mmol})$. Furthermore, the radiolabeled products were shown to be stable in the injectable solutions, as well as in human plasma, for at least $90 \mathrm{~min}$.

Keywords: fluorine; isotopic labeling; positron emission tomography; radiopharmaceuticals; silicon

\section{Introduction}

Positron-Emission-Tomography (PET) is a non-invasive imaging technique using contrast-agents (radiotracers) labeled with radionuclides such as fluorine-18 which undergo positron emission decay. The resulting positron annihilates with an electron, producing two gamma photons, emitted at a $180^{\circ}$ angle, which can be detected in coincidence with high sensitivity, thus yielding a spatial resolution in the mm-range. Although a high number of radiotracers has been developed only a limited number are commonly used as a result of their sometimes cumbersome and difficult synthesis.

The short half-life of many PET-nuclides $\left({ }^{18} \mathrm{~F} \mathrm{t}_{1 / 2}=109.7 \mathrm{~min}\right)$ makes it necessary to produce the radiotracer on site, resulting in high investment costs. The effort for a radiotracer synthesis is nearly independent of the number of patient doses produced per synthesis run. Therefore, PET-centers usually focus on the application of well-established radiotracers such as the glucose derivative ${ }^{18} \mathrm{~F}$ [FDG] $\left({ }^{18} \mathrm{~F}\right.$-2-fluoro-2-desoxyglucose) and only a few large PET-centers are able to provide a large number of other tracers. To bridge this gap, the development of new labeling techniques for the easy introduction of fluorine-18 into radiotracers without costly equipment would be favorable. A promising approach to simplify the radionuclide introduction significantly is the exploitation of the strong silicon-fluorine (Si-F) bond [1,2]. The silicon fluoride acceptor (SiFA) method, based on the efficient isotopic non-radioactive ${ }^{19} \mathrm{~F}$ for radioactive ${ }^{18} \mathrm{~F}$ exchange at the silicon atom, was recently developed and applied for simple one- and two-step ${ }^{18} \mathrm{~F}$-fluorinations of peptides [3]. The radiosynthesis of different SiFA-derivatized peptides (RGD-, octreotate-, as well as a bombesin-analogue) resulted in specific activities of up to $680 \mathrm{GBq} / \mu \mathrm{mol}(18.4 \mathrm{Ci} / \mu \mathrm{mol})$ for the final radiotracers, surprisingly high for a carrier added radiosynthesis [4]. This finding can be explained by DFT (density functional theory) model calculations. The most convenient feature of this SiFA labeling technique is that a final HPLC purification of the radiotracer from the precursor is not necessary, since labeling precursor and labeled product are identical. Another approach with $\mathrm{Si}^{1}{ }^{18} \mathrm{~F}$ bearing building blocks was used for the in vivo evaluation of a Si- ${ }^{18} \mathrm{~F}$-derivatized bombesin derivative in tumor-bearing rodents [5,6]. However, a heating - as well as an HPLC-purification step-were necessary to obtain the final ${ }^{18}$ F-labeled compound in high specific activities. Most recently, the implementation of new functionalized SiFAs for the kit-like ${ }^{18}$ F-labeling of biomolecules was reported [7-10]. In in vivo studies, the use of SiFA-amounts as low as a few nanomoles resulted in ${ }^{18} \mathrm{~F}$-labeled proteins with specific activities of up 
to $10-50 \mathrm{GBq} / \mu \mathrm{mol}(270-1,350 \mathrm{Ci} / \mathrm{mmol})$, which would be suitable for receptor-imaging with PET. In this particular study, we aimed at evaluating the applicability of the SiFA technique for the derivatization of small molecule radiotracers, such as the $\mathrm{D}_{2}$ receptor ligands fallypride (FP, 1), desmethoxyfallypride (DMFP, 2) and raclopride (3). It was expected that the original SiFA building block, which cannot be extensively modified without losing its stability against hydrolysis, might have a detrimental influence on the binding affinity of the SiFA derivatized $\mathrm{D}_{2}$ receptor ligands. Several new Si-F bearing derivatives derived from basic model compounds were analyzed recently and evaluated as to their stability in aqueous solution with regard to the substitution pattern at the silicon atom [11]. The results are consistent with our previous findings that at least two sterically hindered substituents at the silicon atom are necessary to preserve the stability of the silicon-fluorine bond in vitro [3].

With respect to these steric requirements, SiFA derived model compounds of commonly used PET imaging agents were synthesized to evaluate the potential of the SiFA-concept for the syntheses of SiFA-type small molecule radiotracers. The benzamide derivatives $\left[{ }^{18} \mathrm{~F}\right]$ fallypride (1), $\left[{ }^{18} \mathrm{~F}\right]$-desmethoxyfallypride (2) and $\left[{ }^{11} \mathrm{C}\right]$ raclopride (3) radiotracers used for the PET-imaging of the dopaminergic system, were chosen as model compounds for this study [12,13] (Figure 1). All compounds are $\mathrm{D}_{2}$-receptor antagonists, which differ mainly in the receptor affinity, in the nanomolar (desmethoxyfallypride, raclopride) and picomolar range (fallypride), respectively [14]. These imaging agents are used for the diagnosis of different neurological disorders related to the dopaminergic system such as parkinsonism and craving $[15,16]$.

Figure 1. $\mathrm{D}_{2}$-receptor affine benzamide-derivatives used for PET-neuroimaging: $\left[{ }^{18} \mathrm{~F}\right]$-Fallypride (FP, 1); $\left[{ }^{18} \mathrm{~F}\right]$-Desmethoxyfallypride (DMFP, 2 ); $\left[{ }^{11} \mathrm{C}\right]$-Raclopride (3).

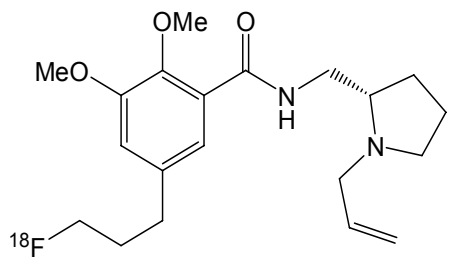

1

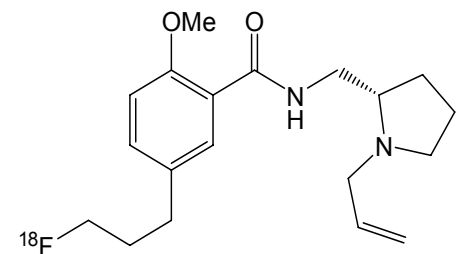

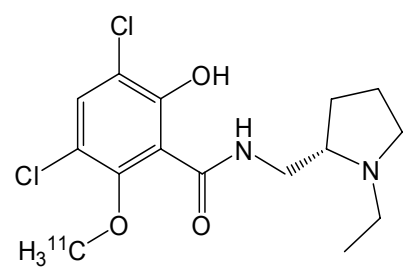

3

Due to the bulkiness of the SiFA-moiety that has to be introduced into the potential radiotracer, the ligand fallypride, having one of the highest affinities to the $\mathrm{D}_{2}$ receptor, was tested first as a scaffold for SiFA derivatization since even a certain loss of target affinity would not necessarily result in an unusable PET radiotracer. The two different strategies applied were: (i) the integration of the SiFA building block into the fallypride/desmethoxyfallypride general structure and (ii) the coupling of an already existing SiFA compound, namely SiFA-maleimide (SiFA-M, [17]), to a fallypride derivatized with an SH moiety at the butyl side chain (Figure 2). Besides the prerequisite of a good binding affinity to the targeted $\mathrm{D}_{2}$-receptor, the radiolabeling has to yield a radiotracer with a sufficiently high specific activity for $\mathrm{D}_{2}$ receptor imaging with PET. In order to simplify the radiosynthesis of the desired ${ }^{18} \mathrm{~F}$ fluorinated radiotracer, we only studied one-step radiosyntheses using the non-radioactive standards directly as the labeling precursors (isotopic exchange reaction). Hence, the amount of the precursor used determines the specific activity (in relation to the amount of radioactivity used for labeling). 
Figure 2. Synthesized SiFA-conjugated Fallypride-derivatives $\mathbf{4 a - c , 5}$.<smiles>C=CCN1CCC[C@H]1CNC(=O)c1cc(CC(C)(C)C)cc(OC)c1OC</smiles>

4a

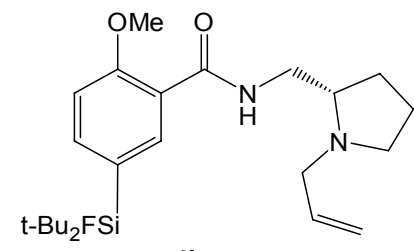

4b

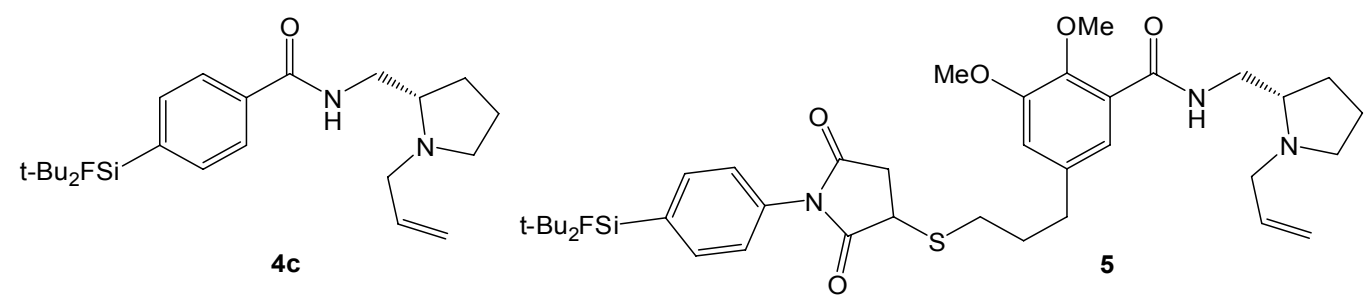

The use of 10 nanomoles precursor would result in specific activities comparable to those of conventionally synthesized ${ }^{18} \mathrm{~F}$ radiotracers. If, e.g., $500 \mathrm{MBq}(13.5 \mathrm{mCi}){ }^{18} \mathrm{~F}$ are incorporated into $10 \mathrm{nmol}$ of the labeling precursor the resulting specific activity would be as high as $50 \mathrm{GBq} / \mu \mathrm{mol}$ $(1,350 \mathrm{Ci} / \mathrm{mmol})$. Consequently, the identification of the lowest limit of the ratio precursor amount/concentration necessary for a sufficient radiochemical yield (introduction of fluorine-18) was the second important focus of this work.

\section{Results and Discussion}

\subsection{Precursor Syntheses}

The preparation of the SiFA-modified carboxylic acids 12a and 12b (Scheme 1) followed a general method described in our previous work [17]. Single crystals of compounds 10b, 12a and 12b suitable for X-ray diffraction analysis were obtained as colorless needles by re-crystallization from diethyl ether/hexane. The molecular structures of these compounds are presented in Figures 3-5, and selected bond distances and bond angles are collected in Table 1.

All compounds crystallized monoclinically with eight $(\mathbf{1 0 b})$ or four $(\mathbf{1 2 a}, \mathbf{1 2 b})$ molecules in the unit cell. There are two crystallographically independent molecules in the unit cell of compound 10b (Figure 3) with one of them being disordered. In Table 1, only the data for the non-disordered molecule are given. The silicon atoms in these compounds are four-coordinate and show each a distorted tetrahedral configuration with average angles of 109.59 (10b), 109.70 (12a) and 109.04 (12b). The largest deviations from the tetrahedral angle are found for $\mathrm{C}(11)-\mathrm{Si}-\mathrm{C}(15)\left(119.40^{\circ}, \mathbf{1 2 b}\right)$ and $\mathrm{F}-\mathrm{Si}-\mathrm{C}(11)\left(104.15^{\circ}, \mathbf{1 2 a}\right)$.

The Si-F distances are similar and fall in the range between 1.6033(11) (12b) and 1.6133(14) (10b) $\AA$. They are slightly longer as compared to $t-\mathrm{BuPh}_{2} \mathrm{SiF}(1.6004(10) \AA)$ but close to the Si-F distances in other SiFA-compounds [17]. Interestingly, intramolecular $\mathrm{O}(1)-\mathrm{H} \cdots \mathrm{O}(11 \mathrm{~A})$ and $\mathrm{O}(11)-\mathrm{H} \cdots \mathrm{O}(1)$ hydrogen bridges (Table 1) link the molecules of compound $\mathbf{1 0 b}$ to form a one-dimensional polymer chain as presented in Figure 3. A noteworthy feature is the asymmetric intramolecular $\mathrm{O}(1)-\mathrm{H} \cdots \mathrm{O}$ 
(2A) hydrogen bridge that links two molecules of 12a and $\mathbf{1 2 b}$, respectively, to give a dimer (Table 2). Such hydrogen bridges are common for solid state structures of $p$-silylarylcarbonic acids [17].

Scheme 1. Synthesis of the silicon-modified carboxylic acids $\mathbf{1 2 a}$ and $\mathbf{1 2 b}$.

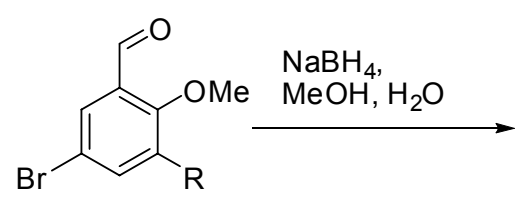

$6 a, b$<smiles>[R]c1cc(Br)cc(CO)c1OC</smiles>

$7 a, b$

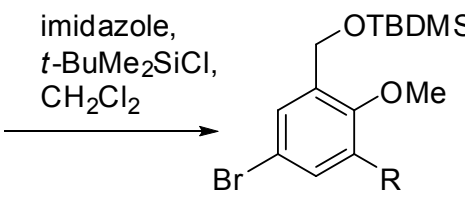

$8 a, b$

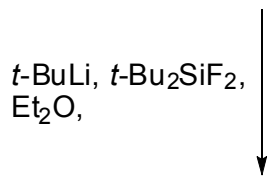<smiles>[R]c1cc([SiH2][R15](C)(C)C)cc(C=O)c1OC</smiles><smiles>[R]c1cc([Se][R15](C)(C)C)cc(CO)c1O[Na]</smiles>

$\mathrm{MeOH}$ $\mathrm{HCl}$ (cat.)<smiles>[R]c1cc([Si]c2ccccc2)cc(CO[R15](C)(C)C)c1OC</smiles>

$10 \mathrm{a}, \mathrm{b}$

$9 a, b$ $\mathrm{KMnO}_{4}, \mathrm{CH}_{2} \mathrm{Cl}_{2}$, $t-\mathrm{BuOH}$, $\mathrm{NaH}_{2} \mathrm{PO}_{4} / \mathrm{H}_{3} \mathrm{PO}_{4}$<smiles>[R]c1cc([SiH2]CCCC)cc(C(=O)O)c1OC</smiles>

a: $\mathrm{R}=\mathrm{H} \quad$ TBDMS $=t-\mathrm{BuMe}_{2} \mathrm{Si}$

b: $\mathrm{R}=\mathrm{OMe} \quad \mathrm{PCC}=\left(\mathrm{C}_{5} \mathrm{H}_{6} \mathrm{~N}\right)^{+}\left(\mathrm{CrClO}_{3}\right)^{-}$

$12 a, b$

Figure 3. Molecular structure of 10b (left) and simplified representation of the intermolecular hydrogen bridges (right). Atomic displacement parameters are drawn at $30 \%$ probability level.
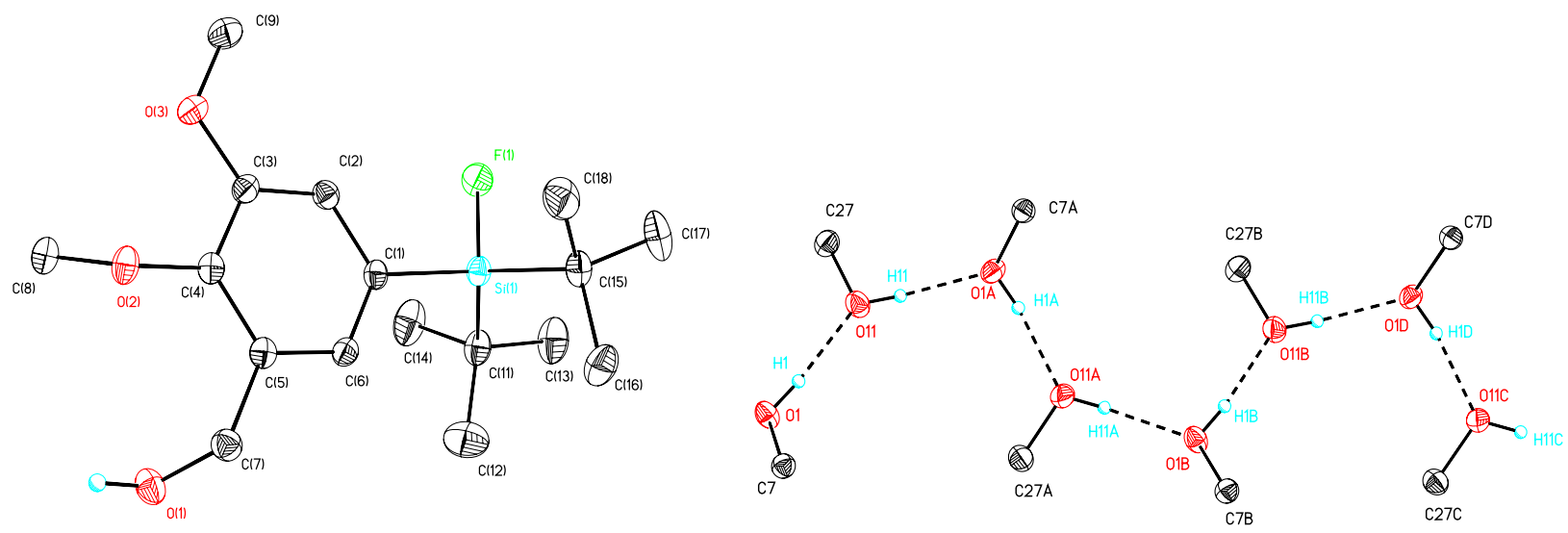
Figure 4. Molecular structure of 12a. Atomic displacement parameters are drawn at 30\% probability level.

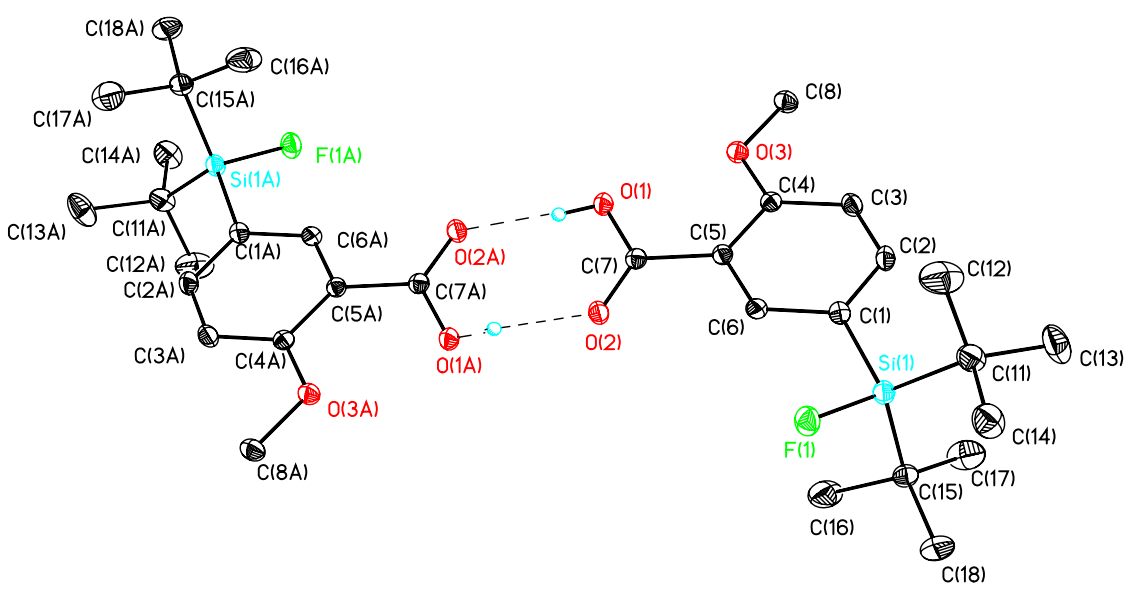

Figure 5. Molecular structure of 12b. Atomic displacement parameters are drawn at 30\% probability level.

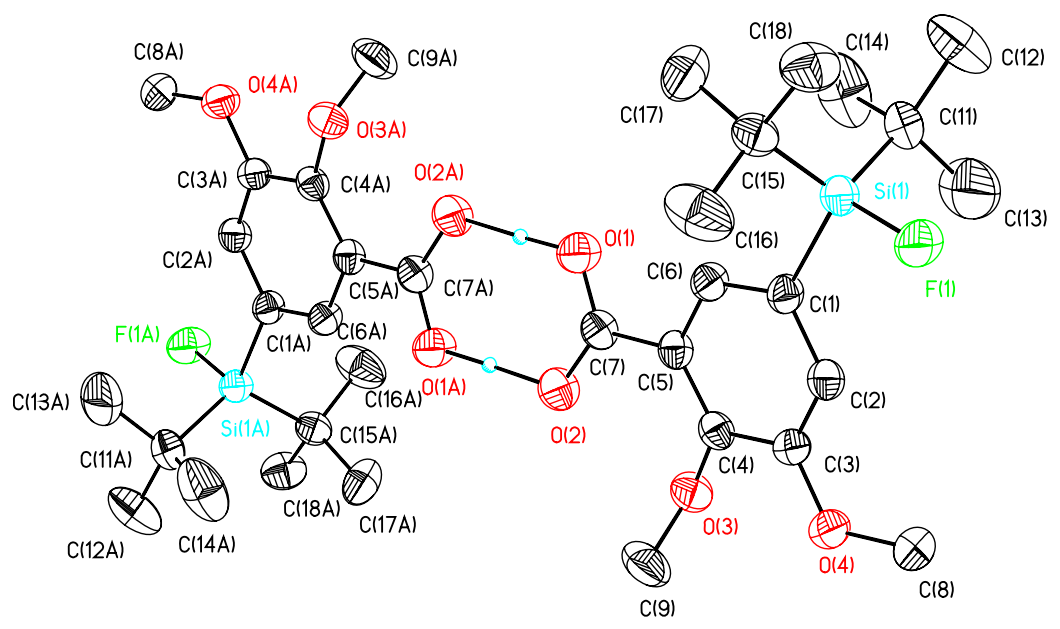

Table 1. Selected bond lengths $[\AA]$ and angles $\left[{ }^{\circ}\right]$ for $\mathbf{1 0 b}, \mathbf{1 2 a}, \mathbf{1 2 b}$.

\begin{tabular}{llll}
\hline Bond lengths $[\AA]$ & 10b & 12a & 12b \\
\hline $\mathrm{Si}(1)-\mathrm{F}(1)$ & $1.6133(13)$ & $1.6125(10)$ & $1.6033(11)$ \\
$\mathrm{Si}(1)-\mathrm{C}(1)$ & $1.8712(19)$ & $1.8696(15)$ & $1.8695(17)$ \\
$\mathrm{Si}(1)-\mathrm{C}(11)$ & $1.893(2)$ & $1.8846(16)$ & $1.872(2)$ \\
$\mathrm{Si}(1)-\mathrm{C}(15)$ & $1.888(2)$ & $1.8911(17)$ & $1.875(2)$ \\
\hline Bond angles [] & & & \\
\hline $\mathrm{F}(1)-\mathrm{Si}(1)-\mathrm{C}(1)$ & $104.78(8)$ & $105.12(6)$ & $104.67(8)$ \\
$\mathrm{F}(1)-\mathrm{Si}(1)-\mathrm{C}(11)$ & $104.97(9)$ & $104.15(7)$ & $105.61(8)$ \\
$\mathrm{F}(1)-\mathrm{Si}(1)-\mathrm{C}(15)$ & $105.23(9)$ & $105.20(6)$ & $104.81(8)$ \\
$\mathrm{C}(1)-\mathrm{Si}(1)-\mathrm{C}(11)$ & $112.55(9)$ & $112.36(7)$ & $109.04(9)$ \\
$\mathrm{C}(1)-\mathrm{Si}(1)-\mathrm{C}(15)$ & $109.59(9)$ & $109.70(7)$ & $111.99(9)$ \\
$\mathrm{C}(11)-\mathrm{Si}(1)-\mathrm{C}(15)$ & $118.44(10)$ & $118.96(7)$ & $119.40(10)$ \\
\hline
\end{tabular}


Table 2. Hydrogen-bonding geometry $\left[\AA,{ }^{\circ}\right]$.

\begin{tabular}{lllllc}
\hline \multicolumn{1}{c}{ Compoun } & D-H...A & d(D-H) & d(H...A & d(D...A) & $<$ (DHA \\
\multicolumn{1}{c}{} & & & ) & & ) \\
\hline $\mathbf{1 0 b}$ & $\mathrm{O}(1)-\mathrm{H}(1) \ldots \mathrm{O}(11 \mathrm{~A})$ & $0.82(3)$ & $1.87(3)$ & $2.682(2)$ & $168(2)$ \\
$\mathbf{1 0 b}$ & $\mathrm{O}(11)-\mathrm{H}(11) \ldots \mathrm{O}(1)$ & $0.83(3)$ & $1.86(3)$ & $2.695(2)$ & $178(3)$ \\
$\mathbf{1 2 a}$ & $\mathrm{O}(1)-\mathrm{H}(1) \ldots \mathrm{O}(2 \mathrm{~A})$ & $0.80(2)$ & $1.84(2)$ & $2.641(2)$ & $173(2)$ \\
$\mathbf{1 2 b}$ & $\mathrm{O}(1)-\mathrm{H}(1) \ldots \mathrm{O}(2 \mathrm{~A})$ & $1.22(4)$ & $1.42(4)$ & $2.640(2)$ & $177(3)$ \\
\hline
\end{tabular}

The test reaction for the coupling of carboxylic acids to $(S)$-(1-allylpyrrolidin-2-yl)methanamine was performed according to a literature procedure [12], using the carboxylic acid 12c [17] (Scheme 2). Dicyclohexylcarbodimide (DCC) was used for the activation of the carboxylic acid and the fallypridederivative was obtained in poor yield of $11 \%$. In order to achieve a higher yield, the more powerful activating agent $N$-hydroxysuccinimide $(\mathrm{HO}-\mathrm{Su})$ was added to the reaction mixture (Scheme 3 ). SiFA-DMFP 4a and SiFA-FP $\mathbf{4 b}$ were obtained in yields of up to $41 \%$ after purification via column chromatography. Both compounds were characterized via two-dimensional NMR spectroscopy and high resolution mass spectrometry. In the latter, the molecular peak was found with high precision.

Scheme 2. Coupling reaction of the SiFA-carboxylic acid 12c to the $(S)$-(1-allyl-pyrrolidin2-yl)methyl-amine.

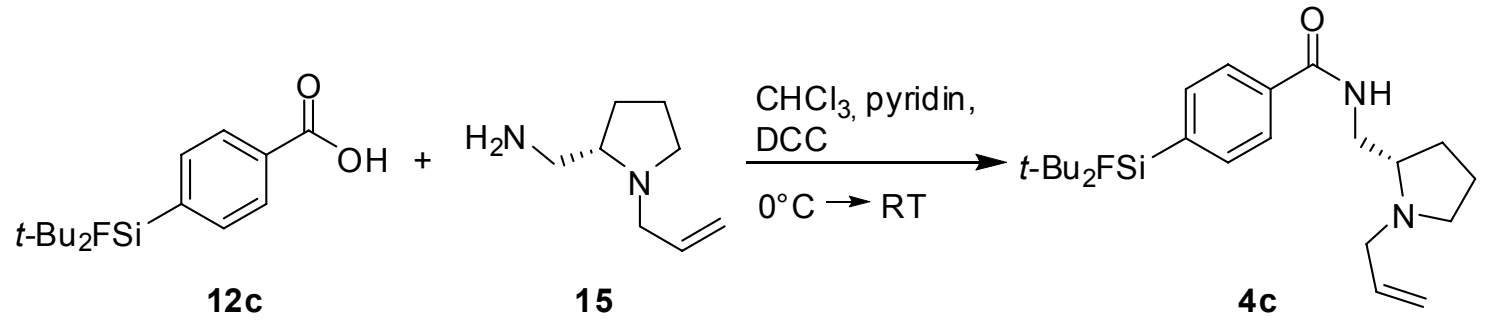

Scheme 3. Coupling reaction of the SiFA-carboxylic acids to the $(S)$-(1-allyl-pyrrolidin-2yl)methyl-amine in the presence of $N$-hydoxy-succinimide.

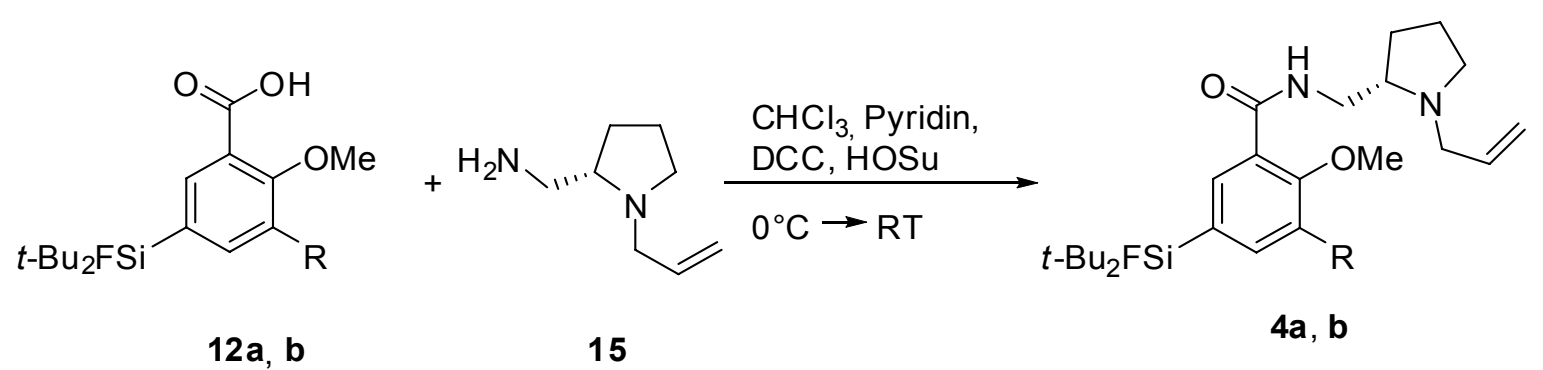

$$
\begin{aligned}
& \text { a: } \mathrm{R}=\mathrm{H} \\
& \mathrm{b}: \mathrm{R}=\mathrm{OMe}
\end{aligned}
$$

SiFA-M (1-(4-(di-tert-butylfluorosilyl)phenyl)-1H-pyrrole-2,5-dione) was synthesized according to a recently described procedure [17] and reacted with FP-Thiol [(S)- $N$-((1-allylpyrrolidin-2-yl)methyl)5-(3-mercaptopropyl)-2,3-dimethoxybenzamide] in a water/acetonitrile mixture at $\mathrm{pH}$ 7.2. This Michael-addition was monitored via analytical HPLC and was completed within 10 min at ambient temperature. After semipreparative HPLC purification and lyophilization, the product SiFA-M-FP, 5, was isolated in 49\% yield and identified via ESI-MS and NMR spectroscopy. 


\subsection{In Vitro Evaluation}

Compounds 4a-c and 5 (SiFA-DMFP 4a, SiFA-FP 4b, SiFA-DDMFP 4c and SiFA-M-FP 5) were tested for their affinity towards the human $\mathrm{D}_{2}$ receptor (Table 3). All tested compounds showed

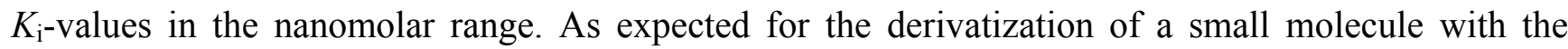
bulky SiFA-moiety, the affinities are reduced by factors ranging between 22 [SiFA-DMFP 4a compared to desmethoxyfallypride (2)], 44 [SiFA-M-FP 5 compared to fallypride (1)] and 342 [SiFA-FP 4b compared to fallypride (1)]. Interestingly, SiFA-DMFP (4a) displays a higher affinity to the receptor compared to SiFA-FP (4b) and SiFA-DDMFP (4c). Among the newly developed substances 4a-c and 5, SiFA-M-FP (5) displays the highest binding affinity which might be explained with the higher distance of the derivatization site ( $\mathrm{SiFA}$ is bound to the butyl side chain) to the receptor binding parts of the molecule. The methoxy moiety, which distinguishes the high affinity tracer fallypride (1) from the medium-affinity tracer desmethoxyfallypride (2) leads to a loss of binding affinity in the pair SiFA-DMFP 4a/SiFA-FP $\mathbf{4 b}$ inversely to the situation with fallypride (1)/desmethoxyfallypride (2). We can therefore assume that the benzoic acid ring system still influences the binding affinity but binds most probably in a different conformation to the binding site at the $\mathrm{D}_{2}$-receptor. However, we chose fallypride (1) as a scaffold for this study, because even an unavoidable decrease in bindingaffinity towards the $\mathrm{D}_{2}$-receptor might still lead to a medium affinity ligand comparable to raclopride (3 - the gold standard for $\mathrm{D}_{2}$-receptor imaging with PET). Therefore, the direct comparison of SiFA-M-FP (5) to $\left[{ }^{11} \mathrm{C}\right]$ raclopride $\left[{ }^{11} \mathbf{C}\right]-3$, which is most frequently used in clinical studies of the dopaminergic system, looked more encouraging: When comparing the medium-affinity $\mathrm{D}_{2}$-receptor radiotracer raclopride $\left(K_{\mathrm{i}}=1.21 \mathrm{nM}\right)$ to $\operatorname{SiFA}-\mathrm{M}-\mathrm{FP}\left(\mathbf{5} ; K_{\mathrm{i}}=4.21\right)$ and $\operatorname{SiFA-DMFP}\left(4 \mathbf{a} ; K_{\mathrm{i}}=13.6 \mathrm{nM}\right)$ the affinity is only reduced by the factor 3.5 and 11 , respectively. Thus, a successful in vivo $\mathrm{D}_{2}$ receptor imaging using radiolabeled SiFA-M-FP (5) or SiFA-DMFP (4a) might be possible.

Table 3. $\mathrm{D}_{2}$-receptor affinities of the developed substances $\mathbf{4 a - c}, \mathbf{5}$.

\begin{tabular}{lc}
\hline Compound & $\boldsymbol{K}_{\mathbf{i}}(\mathbf{n M} \pm \mathbf{S E M} *)$ \\
\hline Fallypride & $0.0965 \pm 0.0153$ \\
Desmethoxyfallypride & $0.630 \pm 0.089$ \\
Raclopride & $1.21 \pm 0.43$ \\
SiFA-DMFP, 4a & $13.6 \pm 4.3$ \\
SiFA-FP, 4b & $33.0 \pm 7.6$ \\
SiFA-DDMFP, 4c & $62.7 \pm 16.9$ \\
SiFA-M-FP, 5 & $4.21 \pm 0.41$ \\
\hline
\end{tabular}

* SEM: standard error of the mean.

\subsection{Radiolabeling}

Radiolabeling reactions based on isotopic exchange usually have the drawback of a limited specific activity (SA), as the precursor cannot be separated from the final product. It is therefore crucial for in vivo applications of the synthesized radiotracer to reduce the precursor amount to the absolute minimum. Our previous studies showed that for radiofluorinations of small molecules such as a SiFA-aldehyde, amounts of 1-5 nmol were sufficient to achieve high radiolabeling yields [4]. For the 
direct labeling of SiFA-derivatized peptides, precursor amounts of 10-25 nmol were necessary [18]. The highest radioactivity incorporation rates were observed when the SiFA radiolabeling was carried out in polar aprotic solvents such as acetonitrile or DMSO. As the SiFA-moiety gets hydrolyzed very quickly under basic conditions, we tested the following two mild labeling procedures in acetonitrile, DMF or DMSO: (a) Kryptofix2.2.2/potassium oxalate $/{ }^{18} \mathrm{~F}^{-}$and (b) tetrabutylammonium bicarbonate $/{ }^{18} \mathrm{~F}^{-}$. Table 4 summarizes the labeling of SiFA-DMFP (4a) under different labeling conditions.

To keep the labeling procedure as simple and convenient as possible, we performed the purification step by using a reversed phase cartridge (SepPak C-18 light) for all tested combinations. We determined the ${ }^{18} \mathrm{~F}$-incroporation of ${ }^{18} \mathrm{~F}^{-}$into $\operatorname{SiFA}$-DMFP (4a) after a 5 min reaction time at room temperature with analytical radio-HPLC using samples of the crude reaction mixture. After dilution with $10 \mathrm{~mL} 1 \mathrm{M}$ HEPES buffer at $\mathrm{pH}=4.0$ (used to prevent hydrolysis) the desired radiotracer was purified using a reversed-phased SepPak-cartridge. The SepPak purification was necessary to remove unreacted ${ }^{18} \mathrm{~F}^{-}$, solvent and $\mathrm{K} 2.2 .2$ potassium oxalate or $\mathrm{TBAHCO}_{3}$ from the product. After washing the cartridge with water, the products could be eluted very efficiently with $1 \mathrm{~mL}$ ethanol and were subsequently diluted with isotonic saline. The radiochemical yields (RCY) were calculated to the start of the synthesis and the radiochemical purity (RCP) analyzed by analytical radio-HPLC. Using SiFA-DMFP (4a) as the precursor, we found radioactivity incorporations in acetonitrile using $\mathrm{TBAHCO}_{3}$ of up to $61 \%$ in the crude reaction mixture (Table 4) and an overall RCY after purification of up to $42 \%$. Under these conditions, the specific activity was calculated to be in the range of $88 \mathrm{GBq} / \mu \mathrm{mol}(2.4 \mathrm{Ci} / \mu \mathrm{mol})$ using a precursor amount of $5 \mathrm{nmol}$ and at least $41 \mathrm{GBq} / \mu \mathrm{mol}(1.1 \mathrm{Ci} / \mu \mathrm{mol})$ using $10 \mathrm{nmol}$ precursor when starting from $\sim 1 \mathrm{GBq}(27 \mathrm{mCi}){ }^{18} \mathrm{~F}$-fluoride. This is in the suitable range for $\mathrm{D}_{2}$-neuroreceptor imaging with PET. The radiochemical purity of all products was $>96 \%$ after purification. Using DMF or DMSO, the ${ }^{18} \mathrm{~F}$-radioactivity incorporation was drastically reduced to less than $25 \%$. More importantly, the desired product could not be purified via cartridge separation. Likewise, the labeling procedure using $\mathrm{K} 2.2 .2$ resulted in a lower relative ${ }^{18} \mathrm{~F}$-incorporation as well as a lower RCY compared to the procedure using $\mathrm{TBAHCO}_{3}$.

Table 4. Radiolabeling of 5-10 nmol SiFA-DMFP (4a), 5 min at ambient temperature.

\begin{tabular}{ccccc}
\hline $\begin{array}{c}\text { Labeling method } \\
\text { (solvent) }\end{array}$ & $\begin{array}{c}\text { Amount of } \\
\text { precursor }\end{array}$ & ${ }^{\mathbf{1 8}} \mathbf{F}$-incorporation $\pm \mathbf{S D} *$ & $\mathbf{R C Y} \pm \mathbf{S D} *$ & $\mathbf{R C P} * *$ \\
\hline $\begin{array}{c}\text { (a) } \mathrm{K} 2.2 .2 * * * \\
\text { (acetonitrile) }\end{array}$ & $10 \mathrm{nmol}$ & $25.3 \pm 2.5 \%$ & $16.7 \pm 1.4 \%$ & $>96 \%$ \\
$\begin{array}{c}\text { (b) } \mathrm{TBAHCO}_{3} \\
\text { (acetonitrile) }\end{array}$ & $10 \mathrm{nmol}$ & $60.7 \pm 3.1 \%$ & $41.8 \pm 5.7 \%$ & $>96 \%$ \\
$\begin{array}{c}\text { (b) } \mathrm{TBAHCO}_{3} \\
\text { (acetonitrile) }\end{array}$ & $5 \mathrm{nmol}$ & $57.2 \pm 6.2 \%$ & $34.6 \pm 5.6 \%$ & $>96 \%$ \\
$\begin{array}{c}\text { (b) } \mathrm{TBAHCO}_{3} \\
(\mathrm{DMSO})\end{array}$ & $10 \mathrm{nmol}$ & $10.2 \pm 0.3 \%$ & n.d. & $<60 \%$ \\
$\begin{array}{c}\text { (b) } \mathrm{TBAHCO} \\
(\mathrm{DMF})\end{array}$ & $10 \mathrm{nmol}$ & $21.4 \pm 4.5 \%$ & n.d. & $<75 \%$ \\
\hline
\end{tabular}

* SD: standard deviation, all experiments were independently performed at least three times;

** after cartridge purification. *** K2.2.2 = Kryptofix2.2.2. 
Using these labeling conditions optimized for $\left[{ }^{18} \mathrm{~F}\right]$-SiFA-DMFP $\left[{ }^{\mathbf{1 8}} \mathbf{F}\right]-\mathbf{4 a}$, we found comparable radiolabeling yields and purities for $\left[{ }^{18} \mathrm{~F}\right]-\operatorname{SiFA}-\mathrm{FP}\left(\left[{ }^{\mathbf{1 8}} \mathbf{F}\right]-\mathbf{4 b}\right)$ and $\left[{ }^{18} \mathrm{~F}\right]-\operatorname{SiFA}-D D M F P\left(\left[{ }^{\mathbf{1 8}} \mathbf{F}\right]-\mathbf{4 c}\right)$, whereas the radiolabeling yields for SiFA-M-FP $\left(\left[{ }^{\mathbf{1 8}} \mathbf{F}\right]-5\right)$ were significantly lower (Table 5).

Table 5. Radiolabeling of $\mathbf{4 a - c}$ and 5, $10 \mathrm{nmol}$, labeling method (b) in acetonitrile.

\begin{tabular}{cccc}
\hline Compound & ${ }^{18} \mathbf{F}$-incorporation $\pm \mathbf{S D} *$ & $\mathbf{R C Y} \pm \mathbf{S D} *$ & $\mathbf{R C P}$ \\
\hline SiFA-DMFP, $\mathbf{4 a}$ & $60.7 \pm 3.1 \%$ & $41.8 \pm 5.7 \%$ & $>96 \%$ \\
SiFA-FP, $\mathbf{4 b}$ & $60.8 \pm 2.5 \%$ & $47.3 \pm 5.9 \%$ & $>94 \%$ \\
SiFA-DDMFP, 4c & $54.2 \pm 6.0 \%$ & $48.4 \pm 0.7 \%$ & $>97 \%$ \\
SiFA-M-FP, $\mathbf{5}$ & $16.6 \pm 10.2 \%$ & n.d. & $<50 \%$ \\
\hline
\end{tabular}

* SD: standard deviation, all experiments were independently performed at least three times.

Moreover, radiolabeled $\left[{ }^{18} \mathrm{~F}\right]-\mathrm{SiFA}-\mathrm{M}-\mathrm{FP}\left[{ }^{18} \mathbf{F}\right]-5$ could not be purified via the SepPak separation method described above. We can only speculate that the chemical design of the phenolic ring system of SiFA-maleimide leads to a significantly different stability of the SiFA-moiety compared to the benzamides 4a-c. This finding is in line with our previous observation that protein labeling using $\left[{ }^{18} \mathrm{~F}\right]$-SiFA-thiol bound to a maleimide-derivatized protein resulted in higher radiolabeling yields than a vice versa labeling of a thiol-derivatized protein with $\left[{ }^{18} \mathrm{~F}\right]-\mathrm{SiFA}$-maleimide.

The chemical purity was determined for all products by analytical HPLC at $214 \mathrm{~nm}$ and showed no side products for all radiolabeled derivatives with a RCP $>94 \%$. The chemical stability of $\left[{ }^{18} \mathrm{~F}\right]-\mathrm{SiFA}-$ DMFP $\left(\left[{ }^{18} \mathrm{~F}\right]-\mathbf{4 a}\right)$, SiFA-FP $\left(\left[{ }^{18} \mathrm{~F}\right]-\mathbf{4 b}\right)$ and SiFA-DDMFP $\left(\left[{ }^{18} \mathrm{~F}\right]-\mathbf{4 c}\right)$ was determined over $4 \mathrm{~h}$ at room temperature by analytical radio-HPLC. Within this time span, no decomposition was detected. The plasma stability was determined for SiFA-DMFP $\left(\left[{ }^{18} \mathrm{~F}\right] \mathbf{4 a}\right)$ over $90 \mathrm{~min}$ displaying no degradation of the product.

\section{Experimental}

\subsection{General}

All solvents used for the syntheses of $\mathbf{4 a}-\mathbf{c}$ (SiFA-DMFP, SiFA-FP, SIFA-DDMFP) were purified by distillation from appropriate drying agents under argon atmosphere. Solvents and chemicals used in the synthesis of 5, SiFA-M-FP, were of analytical grade and used without further purification. Chemicals and solvents used for the labeling experiments were purchased in the highest available grade and were used without further purification. The NMR experiments were carried out with Jeol AS500, Bruker DRX 400, Bruker DRX 300, and Varian Mercury 200 spectrometers. Chemical shifts $(\delta)$ are given in ppm and are referenced to the solvent peaks, with the usual values calibrated against tetramethylsilane $\left({ }^{1} \mathrm{H},{ }^{13} \mathrm{C},{ }^{29} \mathrm{Si}\right)$ and $\mathrm{CFCl}_{3}\left({ }^{19} \mathrm{~F}\right)$. High-resolution mass spectra were obtained by using a Finnigan MAT95Q mass spectrometer and a LTQ Orbitrap mass spectrometer (Thermo Electron) using acetonitrile as the mobile phase. FT infrared spectra were recorded using a Bruker IFS 28 spectrometer. Elemental analyses were performed on a LECO CHNS-932 analyzer. The analytical and semi-preparative HPLC system used was an Agilent 1200 system equipped with a raytest Gabi Star radioactivity detector together with a Chromolith Performance (RP-18e, 100-4.6 mm, Merck, Germany) and a Chromolith (RP-18e, 100-10 mm, Merck, Germany) column, respectively. SiFA-M was 
synthesized according to a published procedure [17]. The synthesis of the thiol-substituted fallypride will be described elsewhere.

\subsection{Crystallography}

Crystals of compounds $\mathbf{1 0 b}, \mathbf{1 2} \mathbf{a}$ and $\mathbf{1 2 b}$ suitable for single-crystal X-ray diffraction analyses were grown by re-crystallization from diethyl ether $n$-hexane. Crystallographic data are summarized in Table 1. Intensity data were collected with a Nonius KappaCCD diffractometer with graphitemonochromated Mo-K $\alpha$ radiation. The data collections covered almost the whole sphere of the reciprocal space with $3(5), 4$ (7 and 8b) sets at different $\kappa$ angles and $227(5), 339$ (7), $494(8 b)$ frames by $\omega$-rotation $\left(\Delta / \omega=1^{\circ}\right)$ at $2 \times 160 \mathrm{~s}(5), 80 \mathrm{~s}(7), 60 \mathrm{~s}(8 \mathrm{~b})$ per frame. Crystal decay was monitored by repeating the initial frames at the end of the data collection. After analysis of the duplicate reflections, there was no indication of any decay. The structures were solved by direct methods (SHELXS97 [19]). Refinement applied full-matrix least-squares methods (SHELXL97). All H atoms were located in the difference Fourier map and their positions were isotropically refined with Uiso constrained at 1.2 times Ueq of the carrier $\mathrm{C}$ atom for non-methyl and 1.5 times Ueq of the carrier $\mathrm{C}$ atom for methyl groups. Atomic scattering factors for neutral atoms and real and imaginary dispersion terms were taken from International Tables for X-ray Crystallography [20]. The figures were created by SHELXTL. Crystallographic data are given in Table 6. Crystallographic data for the structures reported in this paper have been deposited with the Cambridge Crystallographic Data Centre as supplementary material publication No. CCDC-704771, CCDC-704583 and CCDC-704772. Copies of the data can be obtained free of charge on application to CCDC, 12 Union Road, Cambridge, CB2 1EZ, UK (Fax: +44 1223 336033; e-mail: deposit@ccdc.cam.ac.uk).

Table 6. Crystallographic data for $10 a, 12 a$ and $\mathbf{1 2 b}$.

\begin{tabular}{llll}
\hline & $\mathbf{1 0 b}$ & $\mathbf{1 2 a}$ & $\mathbf{1 2 b}$ \\
\hline Empirical formula & $\mathrm{C}_{17} \mathrm{H}_{29} \mathrm{FO}_{3} \mathrm{Si}$ & $\mathrm{C}_{16} \mathrm{H}_{25} \mathrm{FO}_{3} \mathrm{Si}$ & $\mathrm{C}_{17} \mathrm{H}_{27} \mathrm{FO}_{4} \mathrm{Si}$ \\
Formula mass $[\mathrm{g} / \mathrm{mol}]$ & 328.49 & 312.45 & 342.48 \\
Crystal system & monoclinic & monoclinic & monoclinic \\
Crystal size & $0.44 \times 0.28 \times 0.10$ & $0.40 \times 0.28 \times 0.20$ & $0.28 \times 0.24 \times 0.20$ \\
Space group & $\mathrm{P} 21 / \mathrm{c}$ & $\mathrm{P} 21 / \mathrm{n}$ & $\mathrm{P} 21 / \mathrm{c}$ \\
$\mathrm{a}[\AA]$ & $8.0498(3)$ & $6.91101(14)$ & $12.866(3)$ \\
$\mathrm{b}[\AA]$ & $35.1976(15)$ & $16.975(3)$ & $8.1150(16)$ \\
$\mathrm{c}[\AA]$ & $13.5997(7)$ & $14.529(3)$ & $19.412(4)$ \\
$\beta\left[{ }^{\circ}\right]$ & $102.644(2)$ & $94.46(3)$ & $108.51(3)$ \\
$\mathrm{V}\left[\AA^{3}\right]$ & $3759.8(3)$ & $1699.3(6)$ & $1921.9(7)$ \\
$\mathrm{Z}$ & 8 & 4 & 4 \\
$\rho_{\text {calcd }}\left[\mathrm{m}^{3} / \mathrm{m}^{3}\right]$ & 1.161 & 1.221 & 1.184 \\
$\mu\left[\mathrm{mm}^{-1}\right]$ & 0.143 & 0.155 & 0.146 \\
$\mathrm{~F}(000)$ & 1424 & 672 & 736 \\
$\theta$ range $\left[{ }^{\circ}\right]$ & $1.64-27.79$ & $2.78-27.48$ & $2.74-27.48$ \\
Index ranges & $-16 \leq \mathrm{h} \leq 17$ & $-8 \leq \mathrm{h} \leq 8$ & $-15 \leq \mathrm{h} \leq 15$ \\
& $-44 \leq \mathrm{k} \leq 46$ & $-22 \leq \mathrm{k} \leq 22$ & $-10 \leq \mathrm{k} \leq 10$ \\
& $-8 \leq 1 \leq 10$ & $-18 \leq 1 \leq 18$ & $-25 \leq 1 \leq 25$ \\
\hline
\end{tabular}


Table 1. Cont.

\begin{tabular}{llll}
\hline & $\mathbf{1 0 b}$ & $\mathbf{1 2 a}$ & $\mathbf{1 2 b}$ \\
\hline $\begin{array}{l}\text { No. of reflections } \\
\text { collected }\end{array}$ & 26113 & 17951 & 17285 \\
$\begin{array}{l}\text { Completeness of } \theta_{\max } \\
{[\%]}\end{array}$ & 97.3 & 99.8 & 99.8 \\
$\begin{array}{l}\text { No. of independent } \\
\text { reflections / } \mathrm{R}_{\text {int. }}\end{array}$ & $8677 / 0.037$ & $3872 / 0.022$ & $4401 / 0.022$ \\
$\begin{array}{l}\text { No. of reflections } \\
\text { observed with }\end{array}$ & 6140 & 2389 & 1602 \\
$\begin{array}{l}\mathrm{I}>2 \sigma(\mathrm{I})] \\
\text { No. of refined }\end{array}$ & 443 & & \\
$\begin{array}{l}\text { parameters } \\
\text { GoF }\left(\mathrm{F}^{2}\right)\end{array}$ & & & \\
$\mathrm{R}_{1}(\mathrm{~F})[\mathrm{I}>2 \sigma(\mathrm{I})]$ & 0.0517 & 200 & 211 \\
$\mathrm{wR}\left(\mathrm{F}^{2}\right)($ all data $)$ & 0.1409 & 0.900 & 0.729 \\
$(\Delta / \sigma)_{\max }$ & 0.001 & 0.0362 & 0.0364 \\
Largest differnce & $0.448 /-0.251$ & 0.0924 & 0.0905 \\
peak/hole $\left[\mathrm{e} / \AA^{3}\right]$ & & 0.000 & 0.000 \\
& & $0.199 /-0.237$ & $0.106 /-0.171$ \\
\hline
\end{tabular}

\subsection{Chemistry}

(5-Bromo-2-methoxyphenyl)methanol (7a). A solution of sodium borohydride $(0.94 \mathrm{~g}, 24.8 \mathrm{mmol}$, 1.0 equiv.) in $\mathrm{H}_{2} \mathrm{O}(30 \mathrm{~mL})$ was added to a solution of the benzaldehyde derivative $6 \mathbf{6}(5.33 \mathrm{~g}, 24.8 \mathrm{mmol})$ in methanol $(200 \mathrm{~mL})$. After stirring at room temperature for $24 \mathrm{~h}$, methanol was evaporated and the aqueous residue was diluted with diethyl ether $(200 \mathrm{~mL})$. The aqueous phase was extracted with diethyl ether $(3 \times 100 \mathrm{~mL})$, the combined organic layers were dried with $\mathrm{MgSO}_{4}$, filtered and the filtrate was evaporated to afford $7 \mathbf{a}(5.06 \mathrm{~g}, 23.31 \mathrm{mmol}, 94 \%)$ as colourless oil. ${ }^{1} \mathrm{H}-\mathrm{NMR}(400.13 \mathrm{MHz}$, $\left.\mathrm{CDCl}_{3}\right): \delta(\mathrm{ppm})=7.39\left(\mathrm{~d},{ }^{4} J(1 \mathrm{H}-1 \mathrm{H})=2.4 \mathrm{~Hz}, 1 \mathrm{H}, \mathrm{C}(6) \mathrm{H}\right), 7.33\left(\mathrm{dd},{ }^{3} J(1 \mathrm{H}-1 \mathrm{H})=8.8 \mathrm{~Hz}\right.$, $\left.{ }^{4} J(1 \mathrm{H}-1 \mathrm{H})=2.4 \mathrm{~Hz}, 1 \mathrm{H}, \mathrm{C}(4) \mathrm{H}\right), 6.72\left(\mathrm{~d},{ }^{3} J(1 \mathrm{H}-1 \mathrm{H})=8.8 \mathrm{~Hz}, 1 \mathrm{H}, \mathrm{C}(3) \mathrm{H}\right), 4.61\left(\mathrm{~s}, 2 \mathrm{H}, \mathrm{CH}_{2}\right)$, $3.81\left(\mathrm{~s}, 3 \mathrm{H}, \mathrm{OCH}_{3}\right), 2.35(\mathrm{~s}, 1 \mathrm{H}, \mathrm{OH})$.

(5-Bromo-2,3-dimethoxyphenyl)methanol (7b). The procedure was analogous to the synthesis of $7 \mathbf{a}$. The benzaldehyde derivative $\mathbf{6 b}(5.35 \mathrm{~g}, 21.83 \mathrm{mmol})$ gave alcohol $7 \mathbf{b}(5.04 \mathrm{~g}, 20.40 \mathrm{mmol}, 93 \%)$ as a colourless oil. ${ }^{1} \mathrm{H}-\mathrm{NMR}\left(200.13 \mathrm{MHz}, \mathrm{CDCl}_{3}\right): \delta(\mathrm{ppm})=7.05\left(\mathrm{~d},{ }^{4} J(1 \mathrm{H}-1 \mathrm{H})=2.3 \mathrm{~Hz}, 1 \mathrm{H}, \mathrm{C}(4) \mathrm{H}\right)$, $6.93\left(\mathrm{~d},{ }^{4} J(1 \mathrm{H}-1 \mathrm{H})=2.3 \mathrm{~Hz}, 1 \mathrm{H}, \mathrm{C}(6) \mathrm{H}\right), 4.59\left(\mathrm{~d},{ }^{3} J(1 \mathrm{H}-1 \mathrm{H})=5.6 \mathrm{~Hz}, 2 \mathrm{H}, \mathrm{CH}_{2}\right), 3.80\left(\mathrm{~s}, 3 \mathrm{H}, \mathrm{OCH}_{3}\right)$, $3.78\left(\mathrm{~s}, 3 \mathrm{H}, \mathrm{OCH}_{3}\right), 2.93\left(\mathrm{t},{ }^{3} J(1 \mathrm{H}-1 \mathrm{H})=5.6 \mathrm{~Hz}, 1 \mathrm{H}, \mathrm{OH}\right)$.

(5-Bromo-2-methoxybenzyloxy)(tert-butyl)dimethylsilane (8a). To a solution of 7a (5.00 g, $23.00 \mathrm{mmol})$ in dichloromethane $(150 \mathrm{~mL})$ imidazole (2.03 g, $29.89 \mathrm{mmol}, 1.3$ equiv.) was added and the suspension was stirred at ambient temperature for $10 \mathrm{~min}$. $t$-Butyldimethylchlorosilane $\left(t-\mathrm{BuMe}_{2} \mathrm{SiCl}, 4.16 \mathrm{~g}\right.$, 27.59 mmol, 1.2 equiv.) was added and stirring was continued for $20 \mathrm{~h}$. For work-up the mixture was diluted with $\mathrm{H}_{2} \mathrm{O}(40 \mathrm{~mL})$ and the aqueous phase was extracted with dichloromethane $(3 \times 50 \mathrm{~mL})$. The combined organic layers were dried with $\mathrm{MgSO}_{4}$, filtered and the solvent was evaporated to afford 
8a (7.10 g, $21.43 \mathrm{mmol}, 93 \%)$ as a red oil. ${ }^{1} \mathrm{H}-\mathrm{NMR}\left(400.13 \mathrm{MHz}, \mathrm{CDCl}_{3}\right): \delta(\mathrm{ppm})=7.57(\mathrm{~d}$, $\left.{ }^{4} J\left({ }^{1} \mathrm{H}-{ }^{1} \mathrm{H}\right)=2.5 \mathrm{~Hz}, 1 \mathrm{H}, \mathrm{C}(6) \mathrm{H}\right), 7.29\left(\mathrm{dd},{ }^{4} J\left({ }^{1} \mathrm{H}-{ }^{1} \mathrm{H}\right)=2.5 \mathrm{~Hz},{ }^{3} J\left({ }^{1} \mathrm{H}-{ }^{1} \mathrm{H}\right)=8.6 \mathrm{~Hz}, 1 \mathrm{H}, \mathrm{C}(4) \mathrm{H}\right), 6.66(\mathrm{~d}$, $\left.{ }^{3} J\left({ }^{1} \mathrm{H}^{1} \mathrm{H}\right)=8.6 \mathrm{~Hz}, 1 \mathrm{H}, \mathrm{C}(3) \mathrm{H}\right), 4.71\left(\mathrm{~s}, 2 \mathrm{H}, \mathrm{CH}_{2}\right), 3.77\left(\mathrm{~s}, 3 \mathrm{H}, \mathrm{OCH}_{3}\right), 0.97\left(\mathrm{~s}, 9 \mathrm{H}, \mathrm{CCH}_{3}\right)$, $0.13\left(\mathrm{~s}, 6 \mathrm{H}, \mathrm{SiCH}_{3}\right) .{ }^{13} \mathrm{C}[1 \mathrm{H}]-\mathrm{NMR}\left(100.63 \mathrm{MHz}, \mathrm{CDCl}_{3}\right): \delta(\mathrm{ppm})=154.9(\mathrm{~s}, \mathrm{C}(2)), 132.2(\mathrm{~s}, \mathrm{C}(6))$, 130.0 (s, C(4)), 129.5 (s, C(1)), 113.0 (s, C(3)), 111.1 (s, C(5)), 59.7 (s, CH2), 55.3 (s, OCH3), 26.0 (s, CCH3), 18.5 (s, C(CH3)3, -5.3 (s, SiCH3).

(5-Bromo-2,3-dimethoxybenzyloxy)(tert-butyl)dimethylsilane $(\mathbf{8 b})$. The procedure was analogous to the synthesis of $\mathbf{8 a}$. The benzyl alcohol derivative $\mathbf{7 b}(4.93,19.95 \mathrm{mmol})$ gave the silylated alcohol $\mathbf{8 b}$ $(5.88 \mathrm{~g}, 16.27 \mathrm{mmol}, 82 \%)$ as a slightly yellowish oil. ${ }^{1} \mathrm{H}-\mathrm{NMR}\left(400.13 \mathrm{MHz}, \mathrm{CDCl}_{3}\right): \delta(\mathrm{ppm})=7.08$ $\left(\mathrm{d},{ }^{4} \mathrm{~J}\left({ }^{1} \mathrm{H}-{ }^{1} \mathrm{H}\right)=2.3 \mathrm{~Hz}, 1 \mathrm{H}, \mathrm{C}(4) \mathrm{H}\right), 6.82\left(\mathrm{~d},{ }^{4} J\left({ }^{1} \mathrm{H}-{ }^{1} \mathrm{H}\right)=2.2 \mathrm{~Hz}, 1 \mathrm{H}, \mathrm{C}(6) \mathrm{H}\right), 4.62\left(\mathrm{~s}, 2 \mathrm{H}, \mathrm{CH}_{2}\right), 3.72$ (s, 3H, $\left.\mathrm{OCH}_{3}\right), 3.67$ (s, 3H, $\left.\mathrm{OCH}_{3}\right), 0.83$ (s, 9H, CCH3), 0.00 (s, 6H, $\mathrm{SiCH}_{3}$ ).

Di-tert-Butyl(3-((tert-butyldimethylsilyloxy)methyl)-4-methoxyphenyl)fluorosilane (9a). To a stirred solution of $8 \mathbf{a}(5.00 \mathrm{~g}, 15.09 \mathrm{mmol})$ in dry diethyl ether $(150 \mathrm{~mL}), t$-BuLi $(17.8 \mathrm{~mL}, 1.7 \mathrm{~mol} / \mathrm{L}$, $30.18 \mathrm{mmol}, 2.0$ equiv.) was added dropwise at $-78{ }^{\circ} \mathrm{C}$. After stirring for $10 \mathrm{~min} t-\mathrm{Bu}_{2} \mathrm{SiF}_{2}(3.00 \mathrm{~g}$, $16.60 \mathrm{mmol}, 1.1$ equiv.) was added and stirring was continued for $19 \mathrm{~h}$ while the reaction mixture was allowed to warm to ambient temperature. The mixture was washed with $\mathrm{H}_{2} \mathrm{O}(50 \mathrm{~mL})$ and the aqueous phase was extracted with diethylether $(3 \times 50 \mathrm{~mL})$. The combined organic layers were dried with $\mathrm{MgSO}_{4}$, filtered and the solvent was evaporated to afford 9a $(5.77 \mathrm{~g}, 13.98 \mathrm{mmol}, 93 \%)$ as a colourless oil. ${ }^{1} \mathrm{H}-\mathrm{NMR}\left(300.13 \mathrm{MHz}, \mathrm{CDCl}_{3}\right): \delta(\mathrm{ppm})=7.64(\mathrm{~s}, 1 \mathrm{H}, \mathrm{C}(6) \mathrm{H}), 7.38\left(\mathrm{~d},{ }^{3} J(1 \mathrm{H}-1 \mathrm{H})=8.1 \mathrm{~Hz}, 1 \mathrm{H}\right.$, $\mathrm{C}(4) \mathrm{H}), 6.73\left(\mathrm{~d},{ }^{3} J\left({ }^{1} \mathrm{H}-{ }^{1} \mathrm{H}\right)=8.6 \mathrm{~Hz}, 1 \mathrm{H}, \mathrm{C}(3) \mathrm{H}\right), 4.69\left(\mathrm{~s}, 2 \mathrm{H}, \mathrm{CH}_{2}\right), 3.70\left(\mathrm{~s}, 3 \mathrm{H}, \mathrm{OCH}_{3}\right), 0.96(\mathrm{~s}, 18 \mathrm{H}$, $\left.\mathrm{CCH}_{3}\right), 0.85\left(\mathrm{~s}, 9 \mathrm{H}, \mathrm{CCH}_{3}\right), 0.00\left(\mathrm{~s}, 6 \mathrm{H}, \mathrm{SiCH}_{3}\right) \cdot{ }^{13} \mathrm{C}[1 \mathrm{H}]-\mathrm{NMR}\left(75.48 \mathrm{MHz}, \mathrm{CDCl}_{3}\right): \delta(\mathrm{ppm})=157.7$ $(\mathrm{s}, \mathrm{C}(2)), 134.4\left(\mathrm{~d},{ }^{3} J\left({ }^{13} \mathrm{C}-{ }^{19} \mathrm{~F}\right)=3.9 \mathrm{~Hz}, \mathrm{C}(6)\right), 132.4\left(\mathrm{~d},{ }^{3} J\left({ }^{13} \mathrm{C}-{ }^{19} \mathrm{~F}\right)=4.5 \mathrm{~Hz}, \mathrm{C}(4)\right), 129.3(\mathrm{~s}, \mathrm{C}(1))$, $124.3\left(\mathrm{~d},{ }^{2} J\left({ }^{13} \mathrm{C}-{ }^{19} \mathrm{~F}\right)=13.9 \mathrm{~Hz}, \mathrm{C}(5)\right), 109.2(\mathrm{~s}, \mathrm{C}(3)), 60.5\left(\mathrm{~s}, \mathrm{CH}_{2}\right), 55.3\left(\mathrm{~s}, \mathrm{OCH}_{3}\right), 27.8\left(\mathrm{~s}, \mathrm{CCH}_{3}\right)$, $26.4\left(\mathrm{~s}, \mathrm{CCH}_{3}\right), 20.8\left(\mathrm{~d},{ }^{2} J\left({ }^{13} \mathrm{C}-{ }^{19} \mathrm{~F}\right)=12.5 \mathrm{~Hz}, \mathrm{C}\left(\mathrm{CH}_{3}\right)_{3}\right), 18.8\left(\mathrm{~s}, \mathrm{C}\left(\mathrm{CH}_{3}\right)_{3},-4.9\left(\mathrm{~s}, \mathrm{SiCH}_{3}\right) .{ }^{19} \mathrm{~F}-\mathrm{NMR}\right.$ $\left(282.38 \mathrm{MHz} \mathrm{CDCl}_{3}\right): \delta(\mathrm{ppm})=-189.1\left(\mathrm{~s},{ }^{1} J\left({ }^{19} \mathrm{~F}_{-}{ }^{29} \mathrm{Si}\right)=297 \mathrm{~Hz}\right) .{ }^{29} \mathrm{Si}-\mathrm{NMR}\left(59.63 \mathrm{MHz}, \mathrm{CDCl}_{3}\right)$ : $\delta(\mathrm{ppm})=20.6\left(\mathrm{~s}, \mathrm{Si}\left(\mathrm{CH}_{3}\right)_{2} \mathrm{tBu}\right), 14.7\left(\mathrm{~d},{ }^{1} J\left({ }^{29} \mathrm{Si}^{-}{ }^{19} \mathrm{~F}\right)=297 \mathrm{~Hz}, \mathrm{SiFtBu}_{2}\right)$. Elemental analysis calculated (\%) for $\mathrm{C}_{22} \mathrm{H}_{41} \mathrm{FO}_{2} \mathrm{Si}_{2}$ (412.73 g/mol): C 64.0, $\mathrm{H}$ 10.0; found (\%): C 63.8, H 9.6. HR-MS (GC-EI): calculated for $\mathrm{C}_{22} \mathrm{H}_{41} \mathrm{O}_{2} \mathrm{~F}^{28} \mathrm{SNa}^{+} 435.2521$, found $435.2530\left[\mathrm{M}+\mathrm{Na}^{+}\right]$.

Di-tert-Butyl(3-((tert-butyldimethylsilyloxy)methyl)-4,5-dimethoxyphenyl)-fluorosilane (9b). To a stirred solution of $\mathbf{8 b}(5.70 \mathrm{~g}, 15.77 \mathrm{mmol})$ in dry diethylether $(150 \mathrm{~mL})$ and dry THF $(50 \mathrm{~mL}) t$-BuLi $\left(18.6 \mathrm{~mL}, 1.7 \mathrm{~mol} / \mathrm{L}, 31.55 \mathrm{mmol}, 2.0\right.$ equiv.) was added dropwise at $-78{ }^{\circ} \mathrm{C}$. After stirring for $5 \mathrm{~min}$ $t-\mathrm{Bu}_{2} \mathrm{SiF}_{2}$ (3.13 g, $17.35 \mathrm{mmol}, 1.1$ equiv.) was added and stirring was continued for $19 \mathrm{~h}$ while the reaction mixture was allowed to warm to ambient temperature. The mixture was concentrated in vacuo and the aqueous residue dissolved in chloroform. The aqueous phase was extracted with chloroform $(4 \times 100 \mathrm{~mL})$ and the combined organic layers were concentrated in vacuo, dried with $\mathrm{MgSO}_{4}$ and filtered. The solvent was evaporated and the crude product was purified by column chromatography (hexane/diethylether $=20 / 1)$ to afford $9 \mathrm{~b}(4.74 \mathrm{~g}, 10.71 \mathrm{mmol}, 68 \%)$ as a colorless oil. ${ }^{1} \mathrm{H}-\mathrm{NMR}$ $\left(200.13 \mathrm{MHz}, \mathrm{CDCl}_{3}\right): \delta(\mathrm{ppm})=7.33(\mathrm{~s}, 1 \mathrm{H}, \mathrm{C}(6) \mathrm{H}), 7.07(\mathrm{~s}, 1 \mathrm{H}, \mathrm{C}(4) \mathrm{H}), 4.82\left(\mathrm{~s}, 2 \mathrm{H}, \mathrm{CH}_{2}\right)$, $3.89\left(\mathrm{~s}, 3 \mathrm{H}, \mathrm{OCH}_{3}\right), 3.87\left(\mathrm{~s}, 3 \mathrm{H}, \mathrm{OCH}_{3}\right), 1.08\left(\mathrm{~s}, 18 \mathrm{H}, \mathrm{CCH}_{3}\right), 0.95\left(\mathrm{~s}, 9 \mathrm{H}, \mathrm{CCH}_{3}\right), 0.11\left(\mathrm{~s}, 6 \mathrm{H}, \mathrm{SiCH}_{3}\right)$. 
${ }^{13} \mathrm{C}\left[{ }^{1} \mathrm{H}\right]-\mathrm{NMR}\left(100.63 \mathrm{MHz}, \mathrm{CDCl}_{3}\right): \delta(\mathrm{ppm})=151.5(\mathrm{~s}, \mathrm{C}(2)), 147.0(\mathrm{~s}, \mathrm{C}(3)), 134.4(\mathrm{~s}, \mathrm{C}(1)), 128.4$ $\left(\mathrm{d},{ }^{2} J\left({ }^{13} \mathrm{C}-{ }^{19} \mathrm{~F}\right)=13.7 \mathrm{~Hz}, \mathrm{C}(5)\right), 125.1\left(\mathrm{~d},{ }^{3} \mathrm{~J}\left({ }^{13} \mathrm{C}-{ }^{19} \mathrm{~F}\right)=4.5 \mathrm{~Hz}, \mathrm{C}(6)\right), 116.5\left(\mathrm{~d},{ }^{3} J\left({ }^{13} \mathrm{C}-{ }^{19} \mathrm{~F}\right)=3.9 \mathrm{~Hz}\right.$, $\mathrm{C}(4)), 60.5\left(\mathrm{~s}, \mathrm{CH}_{2}\right.$ or $\left.\mathrm{OCH}_{3}\right), 60.1\left(\mathrm{~s}, \mathrm{CH}_{2}\right.$ or $\left.\mathrm{OCH}_{3}\right), 55.8\left(\mathrm{~s}, \mathrm{OCH}_{3}\right), 27.4\left(\mathrm{~s}, \mathrm{CCH}_{3}\right), 25.9\left(\mathrm{~s}, \mathrm{CCH}_{3}\right)$, $20.3\left(\mathrm{~d},{ }^{2} J\left({ }^{13} \mathrm{C}-{ }^{19} \mathrm{~F}\right)=12.4 \mathrm{~Hz}, \mathrm{C}\left(\mathrm{CH}_{3}\right)_{3}\right), 18.3\left(\mathrm{~s}, \mathrm{C}\left(\mathrm{CH}_{3}\right)_{3},-5.3\left(\mathrm{~s}, \mathrm{SiCH}_{3}\right) .{ }^{19} \mathrm{~F}-\mathrm{NMR}(282.38 \mathrm{MHz}\right.$, $\left.\mathrm{CDCl}_{3}\right): \delta(\mathrm{ppm})=-189.1\left(\mathrm{~s},{ }^{1} J\left({ }^{19} \mathrm{~F}_{-}{ }^{29} \mathrm{Si}\right)=298 \mathrm{~Hz}\right) \cdot{ }^{29} \mathrm{Si}-\mathrm{NMR}\left(59.63 \mathrm{MHz}, \mathrm{CDCl}_{3}\right): \delta(\mathrm{ppm})=20.7$ $\left(\mathrm{s}, \mathrm{Si}\left(\mathrm{CH}_{3}\right)_{2} t \mathrm{Bu}\right), 14.3\left(\mathrm{~d},{ }^{1} J\left({ }^{29} \mathrm{Si}^{-19} \mathrm{~F}\right)=298 \mathrm{~Hz}, \mathrm{SiF} t \mathrm{Bu}_{2}\right)$. Elemental analysis calculated (\%) for $\mathrm{C}_{23} \mathrm{H}_{43} \mathrm{FO}_{3} \mathrm{Si}_{2}$ (412.73 g/mol): C 62.4, $\mathrm{H}$ 9.8; found (\%): C 62.2, H 9.6. HR-MS (GC-EI): calculated for $\mathrm{C}_{23} \mathrm{H}_{43} \mathrm{O}_{3} \mathrm{~F}^{28} \mathrm{SiNa}^{+}$465.2627, found $465.2638\left[\mathrm{M}+\mathrm{Na}^{+}\right]$.

(5-(di-tert-Butylfluorosilyl)-2-methoxyphenyl)methanol (10a). To a stirred solution of 9a (4.90 g, $11.88 \mathrm{mmol})$ in methanol $(250 \mathrm{~mL})$ catalytic amounts of concentrated $\mathrm{HCl}$ was added. After stirring at room temperature for $19 \mathrm{~h}$, methanol was evaporated and the residue dissolved in $\mathrm{H}_{2} \mathrm{O}$ and diethyl ether. The aqueous phase was extracted with diethyl ether $(3 \times 50 \mathrm{~mL})$ and the combined organic layers were washed with saturated $\mathrm{NaHCO}_{3}$-solution $(50 \mathrm{~mL})$, dried with $\mathrm{MgSO}_{4}$, and filtrated. The solvent was evaporated to afford $\mathbf{1 0 a}(3.05 \mathrm{~g}, 10.22 \mathrm{mmol}, 86 \%)$ as a colorless oil. ${ }^{1} \mathrm{H}-\mathrm{NMR}(400.13 \mathrm{MHz}$, $\left.\mathrm{CDCl}_{3}\right): \delta(\mathrm{ppm})=7.50\left(\mathrm{~d},{ }^{3} J(1 \mathrm{H}-1 \mathrm{H})=8.1 \mathrm{~Hz}, 1 \mathrm{H}, \mathrm{C}(4) \mathrm{H}\right), 7.47(\mathrm{~s}, 1 \mathrm{H}, \mathrm{C}(6) \mathrm{H}), 6.89(\mathrm{~d}$, $\left.{ }^{3} J(1 \mathrm{H}-1 \mathrm{H})=8.1 \mathrm{~Hz}, 1 \mathrm{H}, \mathrm{C}(3) \mathrm{H}\right), 4.67\left(\mathrm{~d},{ }^{3} J(1 \mathrm{H}-1 \mathrm{H})=6.2 \mathrm{~Hz}, 2 \mathrm{H}, \mathrm{CH}_{2}\right), 3.85\left(\mathrm{~s}, 3 \mathrm{H}, \mathrm{OCH}_{3}\right)$, $2.51\left(\mathrm{t},{ }^{3} J(1 \mathrm{H}-1 \mathrm{H})=6.2 \mathrm{~Hz}, 1 \mathrm{H}, \mathrm{OH}\right), 1.03\left(\mathrm{~s}, 18 \mathrm{H}, \mathrm{CCH}_{3}\right) .{ }^{13} \mathrm{C}\left[{ }^{1} \mathrm{H}\right]-\mathrm{NMR}\left(400.13 \mathrm{MHz}, \mathrm{CDCl}_{3}\right)$ : $\delta(\mathrm{ppm})=158.7(\mathrm{~s}, \mathrm{C}(2)), 135.2\left(\mathrm{~d},{ }^{3} J\left({ }^{13} \mathrm{C}-{ }^{19} \mathrm{~F}\right)=4.3 \mathrm{~Hz}, \mathrm{C}(6)\right), 134.3\left(\mathrm{~d},{ }^{3} J\left({ }^{13} \mathrm{C}-{ }^{19} \mathrm{~F}\right)=4.1 \mathrm{~Hz}, \mathrm{C}(4)\right)$, $128.3(\mathrm{~s}, \mathrm{C}(1)), 124.5\left(\mathrm{~d},{ }^{2} J\left({ }^{13} \mathrm{C}-{ }^{19} \mathrm{~F}\right)=13.9 \mathrm{~Hz}, \mathrm{C}(5)\right), 109.6(\mathrm{~s}, \mathrm{C}(3)), 62.2\left(\mathrm{~s}, \mathrm{CH}_{2}\right), 55.0\left(\mathrm{~s}, \mathrm{OCH}_{3}\right)$, $27.3\left(\mathrm{~s}, \mathrm{CCH}_{3}\right), 20.2\left(\mathrm{~d},{ }^{2} J\left({ }^{13} \mathrm{C}-{ }^{19} \mathrm{~F}\right)=12.4 \mathrm{~Hz}, \mathrm{C}\left(\mathrm{CH}_{3}\right)_{3}\right) .{ }^{19} \mathrm{~F}-\mathrm{NMR}\left(282.38 \mathrm{MHz}, \mathrm{CDCl}_{3}\right)$ : $\delta(\mathrm{ppm})=-189.0\left(\mathrm{~s},{ }^{1} J\left({ }^{19} \mathrm{~F}^{29} \mathrm{Si}\right)=297 \mathrm{~Hz}\right) .{ }^{29} \mathrm{Si}-\mathrm{NMR}\left(59.63 \mathrm{MHz}, \mathrm{CDCl}_{3}\right): \delta(\mathrm{ppm})=14.6(\mathrm{~d}$, $\left.{ }^{1} J\left({ }^{29} \mathrm{Si}-{ }^{19} \mathrm{~F}\right)=297 \mathrm{~Hz}\right)$. Elemental analysis calculated (\%) for $\mathrm{C}_{16} \mathrm{H}_{27} \mathrm{FO}_{2} \mathrm{Si}(298.47 \mathrm{~g} / \mathrm{mol}): \mathrm{C} 64.4, \mathrm{H}$ 9.1; found (\%): C 64.1, H 9.2. IR (KBr): $v\left(\mathrm{~cm}^{-1}\right)=3326(v(\mathrm{OH}))$. HR-MS (GC-EI): calculated for $\mathrm{C}_{16} \mathrm{H}_{27} \mathrm{O}_{2} \mathrm{~F}^{28} \mathrm{Si}^{+}$298.1759, found 298.1761 [M $\mathrm{M}^{+}$.

(5-(di-tert-Butylfluorosilyl)-2,3-dimethoxyphenyl)methanol (10b). The procedure was analogous to the synthesis of 10a starting from the protected alcohol $\mathbf{9 b}(4.69,10.59 \mathrm{mmol})$. The crude product was purified by column chromatography (hexane/diethylether $=3 / 1 \rightarrow$ hexane/diethylether $=2 / 1 \rightarrow$ hexane/diethylether $=1 / 1 \rightarrow$ hexane/diethylether) to afford $\mathbf{1 0 b}(3.13,9.53 \mathrm{mmol}, 90 \%)$ as a white crystalline solid of m.p. $80{ }^{\circ} \mathrm{C} .{ }^{1} \mathrm{H}-\mathrm{NMR}\left(200.13 \mathrm{MHz}, \mathrm{CDCl}_{3}\right): \delta(\mathrm{ppm})=7.14\left(\mathrm{~d},{ }^{4} J\left({ }^{1} \mathrm{H}-{ }^{1} \mathrm{H}\right)=0.9 \mathrm{~Hz}\right.$, $1 \mathrm{H},(\mathrm{C} 4) \mathrm{H}), 7.03\left(\mathrm{~d},{ }^{4} J\left({ }^{1} \mathrm{H}-{ }^{1} \mathrm{H}\right)=0.9 \mathrm{~Hz}, 1 \mathrm{H},(\mathrm{C} 6) \mathrm{H}\right), 4.61\left(\mathrm{~s}, 2 \mathrm{H}, \mathrm{CH}_{2}\right), 3.81\left(\mathrm{~s}, 3 \mathrm{H}, \mathrm{OCH}_{3}\right)$, $\left.3.80\left(\mathrm{~s}, 3 \mathrm{H}, \mathrm{OCH}_{3}\right), 3.17(\mathrm{~s}, 1 \mathrm{H}, \mathrm{OH}), 1.00\left(\mathrm{~s}, 18 \mathrm{H}, \mathrm{CCH}_{3}\right) .{ }^{13} \mathrm{C}^{1} \mathrm{H}\right]-\mathrm{NMR}\left(75.48 \mathrm{MHz}, \mathrm{CDCl}_{3}\right)$ : $\delta(\mathrm{ppm})=152.1(\mathrm{~s},(\mathrm{C} 2)), 148.6(\mathrm{~s},(\mathrm{C} 3)), 134.5(\mathrm{~s},(\mathrm{C} 1)), 129.3\left(\mathrm{~d},{ }^{2} J\left({ }^{13} \mathrm{C}-{ }^{19} \mathrm{~F}\right)=13.6 \mathrm{~Hz},(\mathrm{C} 5)\right), 126.9$ $\left(\mathrm{d},{ }^{3} J\left({ }^{13} \mathrm{C}-{ }^{19} \mathrm{~F}\right)=4.1 \mathrm{~Hz},(\mathrm{C} 4)\right), 117.7\left(\mathrm{~d},{ }^{3} J\left({ }^{13} \mathrm{C}-{ }^{19} \mathrm{~F}\right)=3.9 \mathrm{~Hz},(\mathrm{C} 6)\right), 61.3\left(\mathrm{~s}, \mathrm{CH}_{2}\right), 61.1\left(\mathrm{~s}, \mathrm{OCH}_{3}\right)$, $56.1\left(\mathrm{~s}, \mathrm{OCH}_{3}\right), 27.8\left(\mathrm{~s}, \mathrm{CCH}_{3}\right), 20.6\left(\mathrm{~d},{ }^{2} \mathrm{~J}\left({ }^{13} \mathrm{C}-{ }^{19} \mathrm{~F}\right)=12.4 \mathrm{~Hz}, \mathrm{C}\left(\mathrm{CH}_{3}\right)_{3}\right) .{ }^{19} \mathrm{~F}-\mathrm{NMR}(282.38 \mathrm{MHz}$, $\left.\mathrm{CDCl}_{3}\right): \delta(\mathrm{ppm})=-188.5\left(\mathrm{~s},{ }^{1} J\left({ }^{19} \mathrm{~F}_{-}{ }^{29} \mathrm{Si}\right)=298 \mathrm{~Hz}\right) .{ }^{29} \mathrm{Si}-\mathrm{NMR}\left(59.63 \mathrm{MHz}, \mathrm{CDCl}_{3}\right): \delta(\mathrm{ppm})=14.1$ $\left(\mathrm{d},{ }^{1} J\left({ }^{29} \mathrm{Si}^{1}{ }^{19} \mathrm{~F}\right)=298 \mathrm{~Hz}\right)$. Elemental analysis calculated $(\%)$ for $\mathrm{C}_{17} \mathrm{H}_{29} \mathrm{FO}_{3} \mathrm{Si}(328.19 \mathrm{~g} / \mathrm{mol}): \mathrm{C} 62.2$, H 8.9; found (\%): C 62.0, H 8.9. IR (KBr): $v\left(\mathrm{~cm}^{-1}\right)=3294(v(\mathrm{OH}))$. HR-MS (GC-EI): calculated for $\mathrm{C}_{17} \mathrm{H}_{29} \mathrm{O}_{3} \mathrm{~F}^{28} \mathrm{Si}^{+}$328.1865, found $328.1869\left[\mathrm{M}^{+}\right]$. 
(3-(Bromomethyl)-4-methoxyphenyl)di-tert-butylfluorosilane (10c). The procedure was analogous to the synthesis of 10a starting from 9a $(2.80 \mathrm{~g}, 6.78 \mathrm{mmol})$ and concentrated $\mathrm{HBr}(50 \mathrm{~mL})$. After crystallisation from diethyl ether/hexane, 10c $(1.80 \mathrm{~g}, 4.98 \mathrm{mmol}, 73 \%)$ was obtained as white crystalline solid of m.p. $61{ }^{\circ} \mathrm{C} .{ }^{1} \mathrm{H}-\mathrm{NMR}\left(300.13 \mathrm{MHz}, \mathrm{CDCl}_{3}\right): \delta(\mathrm{ppm})=7.54-7.57(\mathrm{~m}, 2 \mathrm{H}, \mathrm{C}(4) \mathrm{H}$ und $\mathrm{C}(6) \mathrm{H}), 6.93\left(\mathrm{~d},{ }^{3} J\left({ }^{1} \mathrm{H}-{ }^{1} \mathrm{H}\right)=8.7 \mathrm{~Hz}, 1 \mathrm{H}, \mathrm{C}(3) \mathrm{H}\right), 4.61\left(\mathrm{~s}, 2 \mathrm{H}, \mathrm{CH}_{2}\right), 3.94\left(\mathrm{~s}, 3 \mathrm{H}, \mathrm{OCH}_{3}\right), 1.08$ (s, $\left.18 \mathrm{H}, \mathrm{CCH}_{3}\right) .{ }^{13} \mathrm{C}\left[{ }^{1} \mathrm{H}\right]-\mathrm{NMR}\left(75.48 \mathrm{MHz}, \mathrm{CDCl}_{3}\right): \delta(\mathrm{ppm})=159.1 \quad(\mathrm{~s}, \mathrm{C}(2)), 137.1 \quad(\mathrm{~d}$, $\left.{ }^{3} J\left({ }^{13} \mathrm{C}-{ }^{19} \mathrm{~F}\right)=4.1 \mathrm{~Hz}, \mathrm{C}(4)\right), 136.6\left(\mathrm{~d},{ }^{3} J\left({ }^{13} \mathrm{C}-{ }^{19} \mathrm{~F}\right)=4.2 \mathrm{~Hz}, \mathrm{C}(6)\right), 126.1(\mathrm{~s}, \mathrm{C}(1)), 125.2\left(\mathrm{~d},{ }^{2} J\left({ }^{13} \mathrm{C}-{ }^{19} \mathrm{~F}\right)\right.$ $=14.1 \mathrm{~Hz}, \mathrm{C}(5)), 110.8(\mathrm{~s}, \mathrm{C}(3)), 55.9\left(\mathrm{~s}, \mathrm{OCH}_{3}\right), 29.5\left(\mathrm{~s}, \mathrm{CH}_{2}\right), 27.8\left(\mathrm{~s}, \mathrm{CCH}_{3}\right), 20.7(\mathrm{~d}$, $\left.{ }^{2} J\left({ }^{13} \mathrm{C}-{ }^{19} \mathrm{~F}\right)=12.4 \mathrm{~Hz}, \mathrm{C}\left(\mathrm{CH}_{3}\right)_{3}\right) .{ }^{19} \mathrm{~F}-\mathrm{NMR}\left(282.38 \mathrm{MHz}, \mathrm{CDCl}_{3}\right): \delta(\mathrm{ppm})=-189.0 \quad(\mathrm{~s}$, $\left.{ }^{1} J\left({ }^{19} \mathrm{~F}-{ }^{29} \mathrm{Si}\right)=297 \mathrm{~Hz}\right) .{ }^{29} \mathrm{Si}-\mathrm{NMR}\left(59.63 \mathrm{MHz}, \mathrm{CDCl}_{3}\right): \delta(\mathrm{ppm})=14.4\left(\mathrm{~d},{ }^{1} J\left({ }^{29} \mathrm{Si}^{-}{ }^{19} \mathrm{~F}\right)=297 \mathrm{~Hz}\right)$. Elemental analysis calculated (\%) for $\mathrm{C}_{16} \mathrm{H}_{26} \mathrm{BrFOSi}(360.09 \mathrm{~g} / \mathrm{mol})$ : C 53.2, H 7.3; found (\%): C 53.3, $\mathrm{H}$ 6.9. HR-MS (LC-ESI): calculated for $\mathrm{C}_{16} \mathrm{H}_{26} \mathrm{O}^{79} \mathrm{BrF}^{28} \mathrm{Si}[\mathrm{M}]^{+}(\mathrm{m} / z)$ 360.0915, found 360.0922; for $\mathrm{C}_{16} \mathrm{H}_{26} \mathrm{O}^{81} \mathrm{BrF}^{28} \mathrm{Si}[\mathrm{M}]^{+}(\mathrm{m} / z)$ 362.0894, found 362.0907 .

3-(Chloromethyl)-4-methoxyphenyl)-di-tert-butylfluorosilane (10d). The procedure was analogous to the synthesis of 10a starting from 9a (1.99 g, $4.82 \mathrm{mmol}, 1.0$ equiv.) and concentrated $\mathrm{HCl}(50 \mathrm{~mL})$. Crystallisation from diethylether/hexane gave the product $10 \mathrm{~d}(1.16 \mathrm{~g}, 3.66 \mathrm{mmol}, 76 \%)$ as white crystalline solid of m.p. $64{ }^{\circ} \mathrm{C} .{ }^{1} \mathrm{H}-\mathrm{NMR}\left(300.13 \mathrm{MHz}, \mathrm{CDCl}_{3}\right): \delta(\mathrm{ppm})=7.54-7.49(\mathrm{~m}, 2 \mathrm{H}, \mathrm{C}(4) \mathrm{H}$ und $\left.\mathrm{C}(6) \mathrm{H}), 6.89\left(\mathrm{~d},{ }^{3} \mathrm{~J}^{1} \mathrm{H}_{-}{ }^{1} \mathrm{H}\right)=7.9 \mathrm{~Hz}, 1 \mathrm{H}, \mathrm{C}(3) \mathrm{H}\right), 4.64\left(\mathrm{~s}, 2 \mathrm{H}, \mathrm{CH}_{2}\right), 3.85\left(\mathrm{~s}, 3 \mathrm{H}, \mathrm{OCH}_{3}\right), 1.03$ (s, $\left.18 \mathrm{H}, \mathrm{CCH}_{3}\right) .{ }^{13} \mathrm{C}\left[{ }^{1} \mathrm{H}\right]-\mathrm{NMR}\left(100.63 \mathrm{MHz}, \mathrm{CDCl}_{3}\right): \delta(\mathrm{ppm})=158.5(\mathrm{~s}, \mathrm{C}(2)), 136.2(\mathrm{~d}$, $\left.{ }^{3} J\left({ }^{13} \mathrm{C}-{ }^{19} \mathrm{~F}\right)=4.1 \mathrm{~Hz}, \mathrm{C}(4)\right), 136.1\left(\mathrm{~d},{ }^{3} J\left({ }^{13} \mathrm{C}-{ }^{19} \mathrm{~F}\right)=4.2 \mathrm{~Hz}, \mathrm{C}(6)\right), 125.2(\mathrm{~s}, \mathrm{C}(1)), 124.6(\mathrm{~d}$, $\left.{ }^{2} J\left({ }^{13} \mathrm{C}-{ }^{19} \mathrm{~F}\right)=14.1 \mathrm{~Hz}, \mathrm{C}(5)\right), 110.1(\mathrm{~s}, \mathrm{C}(3)), 55.3\left(\mathrm{~s}, \mathrm{OCH}_{3}\right), 41.6\left(\mathrm{~s}, \mathrm{CH}_{2}\right), 27.3\left(\mathrm{~s}, \mathrm{CCH}_{3}\right), 20.2(\mathrm{~d}$, $\left.{ }^{2} J\left({ }^{13} \mathrm{C}-{ }^{19} \mathrm{~F}\right)=12.5 \mathrm{~Hz}, \mathrm{C}\left(\mathrm{CH}_{3}\right)_{3}\right)$. Elemental analysis calculated $(\%)$ for $\mathrm{C}_{16} \mathrm{H}_{26} \mathrm{ClFOSi}(316.91 \mathrm{~g} / \mathrm{mol})$ : C 60.6, H 8.3; found (\%): C 60.8. HR-MS (LC-ESI): calculated for calculated for $\mathrm{C}_{16} \mathrm{H}_{26} \mathrm{OF}^{28} \mathrm{Si}$ $\left[\mathrm{M}-\mathrm{Cl}^{-}\right]^{+}(\mathrm{m} / \mathrm{z}) 281.1732$, found 281.1733 .

5-(di-tert-Butylfluorosilyl)-2-methoxybenzaldehye (11a). To an ice-cooled and stirred suspension of pyridinium chlorochromate (2.86 g, $13.27 \mathrm{mmol}, 3.0$ equiv.) in dry $\mathrm{CH}_{2} \mathrm{Cl}_{2}(150 \mathrm{~mL})$ was added drop-wise within $10 \mathrm{~min}$ a solution of $\mathbf{1 0 a}(1.32 \mathrm{~g}$, $4.42 \mathrm{mmol})$ in dry $\mathrm{CH}_{2} \mathrm{Cl}_{2}(30 \mathrm{~mL})$. The reaction mixture was stirred at room temperature for $2 \mathrm{~h}$. After the reaction mixture had been diluted with diethyl ether $(300 \mathrm{~mL})$, the supernatant solution was decanted and the residue was washed with diethyl ether $(2 \times 100 \mathrm{~mL})$. Filtration of the combined organic layers over a pad of silica and evaporation of the solvent afforded 11a (1.31 g, $4.42 \mathrm{mmol}$, quantitative) as a slightly yellowish amorphous solid, m.p. $38{ }^{\circ} \mathrm{C} .{ }^{1} \mathrm{H}-\mathrm{NMR}\left(400.13 \mathrm{MHz}, \mathrm{CDCl}_{3}\right): \delta(\mathrm{ppm})=10.43(\mathrm{~s}, 1 \mathrm{H}, \mathrm{CHO}), 8.00(\mathrm{~s}, 1 \mathrm{H}, \mathrm{C}(6) \mathrm{H}), 7.73(\mathrm{~d}$, $\left.{ }^{3} J\left({ }^{1} \mathrm{H}-{ }^{1} \mathrm{H}\right)=8.3 \mathrm{~Hz}, 1 \mathrm{H}, \mathrm{C}(4) \mathrm{H}\right), 6.98\left(\mathrm{~d},{ }^{3} J\left({ }^{1} \mathrm{H}-{ }^{1} \mathrm{H}\right)=8.3 \mathrm{~Hz}, 1 \mathrm{H}, \mathrm{C}(3) \mathrm{H}\right), 3.88\left(\mathrm{~s}, 3 \mathrm{H}, \mathrm{OCH}_{3}\right), 0.98$ (s, $\left.18 \mathrm{H}, \mathrm{CCH}_{3}\right) .{ }^{13} \mathrm{C}\left[{ }^{1} \mathrm{H}\right]-\mathrm{NMR}\left(100.63 \mathrm{MHz}, \mathrm{CDCl}_{3}\right): \delta(\mathrm{ppm})=189.6(\mathrm{~s}, \mathrm{CHO}), 162.7$ (s, C(2)), 141.6 $\left(\mathrm{d},{ }^{3} J\left({ }^{13} \mathrm{C}-{ }^{19} \mathrm{~F}\right)=4.1 \mathrm{~Hz}, \mathrm{C}(4)\right), 134.1\left(\mathrm{~d},{ }^{3} J\left({ }^{13} \mathrm{C}-{ }^{19} \mathrm{~F}\right)=4.3 \mathrm{~Hz}, \mathrm{C}(6)\right), 129.9(\mathrm{~s}, \mathrm{C}(1)), 124.8(\mathrm{~d}$, $\left.{ }^{2} J\left({ }^{13} \mathrm{C}-{ }^{19} \mathrm{~F}\right)=14.1 \mathrm{~Hz}, \mathrm{C}(5)\right), 111.1(\mathrm{~s}, \mathrm{C}(3)), 55.4\left(\mathrm{~s}, \mathrm{OCH}_{3}\right), 27.2\left(\mathrm{~s}, \mathrm{CCH}_{3}\right), 20.1\left(\mathrm{~d},{ }^{2} J\left({ }^{13} \mathrm{C}-{ }^{19} \mathrm{~F}\right)=12.4 \mathrm{~Hz}\right.$, $\left.\mathrm{C}\left(\mathrm{CH}_{3}\right)_{3}\right) .{ }^{19} \mathrm{~F}-\mathrm{NMR}\left(282.38 \mathrm{MHz}, \mathrm{CDCl}_{3}\right): \delta(\mathrm{ppm})=-188.6\left(\mathrm{~s},{ }^{1} J\left({ }^{19} \mathrm{~F}-{ }^{29} \mathrm{Si}\right)=298 \mathrm{~Hz}\right) .{ }^{29} \mathrm{Si}-\mathrm{NMR}$ $\left.\left(59.63 \mathrm{MHz}, \mathrm{CDCl}_{3}\right): \delta(\mathrm{ppm})=14.3\left(\mathrm{~d},{ }^{1} \mathrm{~J}^{29} \mathrm{Si}^{19}{ }^{19} \mathrm{~F}\right)=298 \mathrm{~Hz}\right)$. Elemental analysis calculated $(\%)$ for $\mathrm{C}_{16} \mathrm{H}_{27} \mathrm{FO}_{2} \mathrm{Si}(296.45 \mathrm{~g} / \mathrm{mol})$ : C 64.8, H 8.5; found (\%): C 64.0, H 8.7. HR-MS (GC-EI): calculated for $\mathrm{C}_{16} \mathrm{H}_{25} \mathrm{O}_{2} \mathrm{~F}^{28} \mathrm{Si} \mathrm{[M]^{+ }}(\mathrm{m} / \mathrm{z}): 296.1602$; found 296.1601. 
5-(di-tert-Butylfluorosilyl)-2,3-dimethoxybenzaldehyde (11b). The procedure was analogous to the synthesis of 11a. The alcohol $10 \mathrm{~b}(3.04 \mathrm{~g}, 9.25 \mathrm{mmol})$ gave the aldehyde 11b $(3.12 \mathrm{~g}, 9.25 \mathrm{mmol}$, quantitative) as a slightly yellowish amorphous solid of m.p. $73{ }^{\circ} \mathrm{C} .{ }^{1} \mathrm{H}-\mathrm{NMR}\left(400.13 \mathrm{MHz}, \mathrm{CDCl}_{3}\right)$ : $\delta(\mathrm{ppm})=10.36(\mathrm{~s}, 1 \mathrm{H}, \mathrm{CHO}), 7.55(\mathrm{~s}, 1 \mathrm{H}, \mathrm{C}(6) \mathrm{H}), 7.28(\mathrm{~s}, 1 \mathrm{H}, \mathrm{C}(4) \mathrm{H}), 3.93\left(\mathrm{~s}, 3 \mathrm{H}, \mathrm{OCH}_{3}\right), 3.84(\mathrm{~s}$, $\left.3 \mathrm{H}, \mathrm{OCH}_{3}\right), 0.97\left(\mathrm{~s}, 18 \mathrm{H}, \mathrm{CCH}_{3}\right) .{ }^{13} \mathrm{C}\left[{ }^{1} \mathrm{H}\right]-\mathrm{NMR}\left(100.63 \mathrm{MHz}, \mathrm{CDCl}_{3}\right): \delta(\mathrm{ppm})=189.9(\mathrm{~s}, \mathrm{CHO})$, 153.6.7 (s, C(2)), $152.3(\mathrm{~s}, \mathrm{C}(3)), 129.2\left(\mathrm{~d},{ }^{2} J\left({ }^{13} \mathrm{C}-{ }^{19} \mathrm{~F}\right)=14.2 \mathrm{~Hz}, \mathrm{C}(5)\right), 128.9$ (s, C(1)), 124.7 (d, $\left.{ }^{3} J\left({ }^{13} \mathrm{C}-{ }^{19} \mathrm{~F}\right)=4.4 \mathrm{~Hz}, \mathrm{C}(4)\right), 122.9\left(\mathrm{~d},{ }^{3} J\left({ }^{13} \mathrm{C}-{ }^{19} \mathrm{~F}\right)=4.2 \mathrm{~Hz}, \mathrm{C}(6)\right), 62.0\left(\mathrm{~s}, \mathrm{OCH}_{3}\right), 55.4\left(\mathrm{~s}, \mathrm{OCH}_{3}\right), 27.1$ $\left(\mathrm{s}, \mathrm{CCH}_{3}\right), 20.1\left(\mathrm{~d},{ }^{2} J\left({ }^{13} \mathrm{C}-{ }^{19} \mathrm{~F}\right)=12.2 \mathrm{~Hz}, \mathrm{C}\left(\mathrm{CH}_{3}\right)_{3}\right) .{ }^{19} \mathrm{~F}-\mathrm{NMR}\left(282.38 \mathrm{MHz}, \mathrm{CDCl}_{3}\right): \delta(\mathrm{ppm})=-188.2$ $\left(\mathrm{s},{ }^{1} J\left({ }^{19} \mathrm{~F}_{-}{ }^{29} \mathrm{Si}\right)=298.9 \mathrm{~Hz}\right) .{ }^{29} \mathrm{Si}-\mathrm{NMR}\left(59.63 \mathrm{MHz}, \mathrm{CDCl}_{3}\right): \delta(\mathrm{ppm})=13.9\left(\mathrm{~d},{ }^{1} J\left({ }^{29} \mathrm{Si}^{1}{ }^{19} \mathrm{~F}\right)=299.0 \mathrm{~Hz}\right)$. Elemental analysis calculated (\%) for $\mathrm{C}_{17} \mathrm{H}_{27} \mathrm{FO}_{3} \mathrm{Si}(326.48 \mathrm{~g} / \mathrm{mol}$ ): $\mathrm{C}$ 62.5, $\mathrm{H} \mathrm{8.3}$; found (\%): C 62.4, $\mathrm{H}$ 8.4. IR $(\mathrm{KBr}): v(\mathrm{~cm}-1)=1692(v(\mathrm{C}=\mathrm{O}))$. HR-MS (GC-EI): calculated for $\mathrm{C}_{17} \mathrm{H}_{27} \mathrm{O}_{3} \mathrm{FSi}[\mathrm{M}]^{+}(\mathrm{m} / z)$ : 326.1708; found 326.1697.

5-(di-tert-Butylfluorosilyl)-2-methoxybenzoic acid (12a). To a stirred solution of 11a (1.31 g, $4.42 \mathrm{mmol})$ in $\mathrm{CH}_{2} \mathrm{Cl}_{2}(5 \mathrm{~mL})$ and $t$-BuOH $(30 \mathrm{~mL})$ one after another a buffered solution $(30 \mathrm{~mL}, \mathrm{pH}=3)$ of $\mathrm{NaH}_{2} \mathrm{PO}_{4}(1.25 \mathrm{M})$, concentrated $\mathrm{H}_{3} \mathrm{PO}_{4}$ and an aqueous solution of $\mathrm{KMnO}_{4}(50 \mathrm{~mL}, 1 \mathrm{M})$ were added. Stirring was continued at room temperature for $3 \mathrm{~h}$. The reaction mixture was quenched with saturated $\mathrm{Na}_{2} \mathrm{SO}_{3}$-solution $(150 \mathrm{~mL})$ and $\mathrm{HCl}(2 \mathrm{M})$. The latter reagents were added until the mixture turned colorless. After extraction with diethylether $(3 \times 200 \mathrm{~mL})$ the combined organic layers were dried with $\mathrm{MgSO}_{4}$, filtered and the solvent was evaporated to afford 12a $(1.01 \mathrm{~g}, 3.23 \mathrm{mmol}, 73 \%)$ as a white amorphous solid that was re-crystallised from diethyl ether/hexane to give colorless crystals of m.p. $123{ }^{\circ} \mathrm{C} .{ }^{1} \mathrm{H}-\mathrm{NMR}\left(200 \mathrm{MHz}, \mathrm{CDCl}_{3}\right): \delta(\mathrm{ppm})=8.40\left(\mathrm{~d},{ }^{4} J\left({ }^{1} \mathrm{H}-{ }^{1} \mathrm{H}\right)=1.8 \mathrm{~Hz}, 1 \mathrm{H}, \mathrm{C}(6) \mathrm{H}\right), 7.81(\mathrm{dd}$, $\left.{ }^{3} J(1 \mathrm{H}-1 \mathrm{H})=8.3 \mathrm{~Hz},{ }^{4} J\left({ }^{1} \mathrm{H}-{ }^{1} \mathrm{H}\right)=1.8 \mathrm{~Hz}, 1 \mathrm{H}, \mathrm{C}(4) \mathrm{H}\right), 7.09\left(\mathrm{~d},{ }^{3} J\left({ }^{1} \mathrm{H}-{ }^{1} \mathrm{H}\right)=8.3 \mathrm{~Hz}, 1 \mathrm{H}, \mathrm{C}(3) \mathrm{H}\right), 4.09$ (s, $\left.3 \mathrm{H}, \mathrm{OCH}_{3}\right), 1.04\left(\mathrm{~s}, 18 \mathrm{H}, \mathrm{CCH}_{3}\right) \cdot{ }^{13} \mathrm{C}\left[{ }^{1} \mathrm{H}\right]-\mathrm{NMR}\left(100.63 \mathrm{MHz}, \mathrm{CDCl}_{3}\right): \delta(\mathrm{ppm})=165.5(\mathrm{~s}, \mathrm{COOH})$, $159.8(\mathrm{~s}, \mathrm{C}(2)), 140.8\left(\mathrm{~d},{ }^{3} J\left({ }^{13} \mathrm{C}-{ }^{19} \mathrm{~F}\right)=4.0 \mathrm{~Hz}, \mathrm{C}(4)\right), 139.2\left(\mathrm{~d},{ }^{3} J\left({ }^{13} \mathrm{C}-{ }^{19} \mathrm{~F}\right)=4.4 \mathrm{~Hz}, \mathrm{C}(6)\right), 127.1$ $\left(\mathrm{d},{ }^{2} J\left({ }^{13} \mathrm{C}-{ }^{19} \mathrm{~F}\right)=14.3 \mathrm{~Hz}, \mathrm{C}(5)\right), 116.9(\mathrm{~s}, \mathrm{C}(1)), 111.1(\mathrm{~s}, \mathrm{C}(3)), 56.5\left(\mathrm{~s}, \mathrm{OCH}_{3}\right), 27.2\left(\mathrm{~s}, \mathrm{CCH}_{3}\right), 20.1$ $\left(\mathrm{d},{ }^{2} J\left({ }^{13} \mathrm{C}-{ }^{19} \mathrm{~F}\right)=12.2 \mathrm{~Hz}, \mathrm{C}\left(\mathrm{CH}_{3}\right)_{3}\right) .{ }^{19} \mathrm{~F}-\mathrm{NMR}\left(282.38 \mathrm{MHz}, \mathrm{CDCl}_{3}\right): \delta(\mathrm{ppm})=-188.5(\mathrm{~s}$, $\left.{ }^{1} J\left({ }^{19} \mathrm{~F}_{-}{ }^{29} \mathrm{Si}\right)=298 \mathrm{~Hz}\right)$. Elemental analysis calculated $(\%)$ for $\mathrm{C}_{16} \mathrm{H}_{25} \mathrm{FO}_{3} \mathrm{Si}(312.45 \mathrm{~g} / \mathrm{mol}): \mathrm{C} 61.5, \mathrm{H}$ 8.1; found (\%): C 61.1, H 7.9. HR-MS (GC-EI): calculated for $\mathrm{C}_{16} \mathrm{H}_{25} \mathrm{O}_{3} \mathrm{FSi}[\mathrm{M}]_{+}(\mathrm{m} / \mathrm{z})$ : 312.1552 ; found 312.1563. IR $(\mathrm{KBr}): v\left(\mathrm{~cm}^{-1}\right)=2989(v(\mathrm{OH})), 1701(v(\mathrm{C}=\mathrm{O}))$.

5-(di-tert-Butylfluorosilyl)-2,3-dimethoxybenzoic acid (12b). The procedure was analogous to the synthesis of 12a. The aldehyde $11 \mathbf{b}(2.00 \mathrm{~g}, 6.13 \mathrm{mmol})$ gave after re-crystallization from diethylether/hexane the carboxylic acid $\mathbf{1 2 b}(2.02 \mathrm{~g}, 5.90 \mathrm{mmol}, 96 \%)$ as colorless crystals of m.p. $118{ }^{\circ} \mathrm{C} .{ }^{1} \mathrm{H}-\mathrm{NMR}\left(400.13 \mathrm{MHz}, \mathrm{CDCl}_{3}\right): \delta(\mathrm{ppm})=7.91(\mathrm{~s}, 1 \mathrm{H}, \mathrm{C}(6) \mathrm{H}), 7.34(\mathrm{~s}, 1 \mathrm{H}, \mathrm{C}(4) \mathrm{H}), 4.10$ $\left(\mathrm{s}, 3 \mathrm{H}, \mathrm{OCH}_{3}\right), 3.92\left(\mathrm{~s}, 3 \mathrm{H}, \mathrm{OCH}_{3}\right), 1.04\left(\mathrm{~s}, 18 \mathrm{H}, \mathrm{CCH}_{3}\right) .13 \mathrm{C}[1 \mathrm{H}]-\mathrm{NMR}\left(100.63 \mathrm{MHz}, \mathrm{C}_{6} \mathrm{D}_{6}\right)$ : $\delta(\mathrm{ppm})=166.8(\mathrm{~s}, \mathrm{COOH}), 152.4(\mathrm{~s}, \mathrm{C}(2)), 150.2(\mathrm{~s}, \mathrm{C}(3)), 130.1\left(\mathrm{~d},{ }^{2} J\left({ }^{13} \mathrm{C}-{ }^{19} \mathrm{~F}\right)=14.2 \mathrm{~Hz}, \mathrm{C}(5)\right)$, $129.3\left(\mathrm{~d},{ }^{3} J\left({ }^{13} \mathrm{C}-{ }^{19} \mathrm{~F}\right)=4.7 \mathrm{~Hz}, \mathrm{C}(4)\right), 123.3(\mathrm{~s}, \mathrm{C}(1)), 122.0\left(\mathrm{~d},{ }^{3} J\left({ }^{13} \mathrm{C}-{ }^{19} \mathrm{~F}\right)=3.9 \mathrm{~Hz}, \mathrm{C}(6)\right), 61.1$ (s, $\left.\mathrm{OCH}_{3}\right), 55.2\left(\mathrm{~s}, \mathrm{OCH}_{3}\right), 27.1\left(\mathrm{~s}, \mathrm{CCH}_{3}\right), 20.1\left(\mathrm{~d},{ }^{2} \mathrm{~J}\left({ }^{13} \mathrm{C}-{ }^{19} \mathrm{~F}\right)=12.1 \mathrm{~Hz}, \mathrm{C}\left(\mathrm{CH}_{3}\right)_{3}\right) .{ }^{19} \mathrm{~F}-\mathrm{NMR}(282.38$ $\left.\mathrm{MHz}, \mathrm{CDCl}_{3}\right): \delta(\mathrm{ppm})=-187.7\left(\mathrm{~s},{ }^{1} J\left({ }^{19} \mathrm{~F}^{29} \mathrm{Si}\right)=299 \mathrm{~Hz}\right) .{ }^{29} \mathrm{Si}-\mathrm{NMR}\left(59.63 \mathrm{MHz}, \mathrm{CDCl}_{3}\right)$ : $\delta(\mathrm{ppm})=14.3\left(\mathrm{~d},{ }^{1}{ }^{29}\left({ }^{29} \mathrm{Si}^{19} \mathrm{~F}\right)=299 \mathrm{~Hz}\right)$. Elemental analysis calculated $(\%)$ for $\mathrm{C}_{17} \mathrm{H}_{27} \mathrm{O}_{4} \mathrm{FSi}(342.17$ 
g/mol): C 59.6, H 8.0; found (\%): C 59.4, H 7.6. HR-MS (GC-EI): calculated for $\mathrm{C}_{17} \mathrm{H}_{27} \mathrm{O}_{4} \mathrm{FSi}[\mathrm{M}]^{+}$ $(\mathrm{m} / \mathrm{z})$ : 342.1657; found 342.1641. IR $(\mathrm{KBr}): v\left(\mathrm{~cm}^{-1}\right)=2974(v(\mathrm{OH})), 1685(v(\mathrm{C}=\mathrm{O}))$.

(S)-1-Allylpyrrolidine-2-carboxamide (14). The synthesis followed the same procedure as described in the literature [12]. The reaction of (S)-pyrrolinamide $13(1.03 \mathrm{~g}, 9.02 \mathrm{mmol})$ with allyl iodide $(0.83 \mathrm{~mL}$, $9.02 \mathrm{mmol}, 1.0$ equiv.) gave compound 14 (1.29 g, $8.37 \mathrm{mmol}, 93 \%)$ as white amorphous solid. ${ }^{1} \mathrm{H}-\mathrm{NMR}\left(400.13 \mathrm{MHz}, \mathrm{CDCl}_{3}\right): \delta(\mathrm{ppm})=7.19(\mathrm{~s}, 1 \mathrm{H}, \mathrm{NH}-\mathrm{H}), 6.00$ (s, 1H, NH-H), 5.87-5.76 (m, $\left.1 \mathrm{H}, \mathrm{CH}=\mathrm{CH}_{2}\right), 5.20-5.04\left(\mathrm{~m}, 2 \mathrm{H}, \mathrm{CH}=\mathrm{CH}_{2}\right), 3.28\left(\mathrm{dd},{ }^{3} J_{1}\left({ }^{1} \mathrm{H}-{ }^{1} \mathrm{H}\right)=13.6 \mathrm{~Hz},{ }^{3} J_{2}\left({ }^{1} \mathrm{H}-{ }^{1} \mathrm{H}\right)=5.9 \mathrm{~Hz}, 1 \mathrm{H}\right.$, $\mathrm{CH}), 3.14-3.07$ (m, 1H, CH-H), 3.06-2.99 (m, 2H, N-CH $-\mathrm{CH}), 2.37-2.27$ (m, 1H, CH-H), 2.21-2.09 $(\mathrm{m}, 1 \mathrm{H}, \mathrm{CH}-\mathrm{H}), 1.91-1.81(\mathrm{~m}, 1 \mathrm{H}, \mathrm{CH}-\mathrm{H}), 1.78-1.69\left(\mathrm{~m}, 2 \mathrm{H}, \mathrm{CH}_{2}\right) .{ }^{13} \mathrm{C}\left[{ }^{1} \mathrm{H}\right]-\mathrm{NMR}(100.63 \mathrm{MHz}$, $\left.\mathrm{CDCl}_{3}\right): \delta(\mathrm{ppm})=178.3\left(\mathrm{~s}, \mathrm{CONH}_{2}\right), 135.1\left(\mathrm{~s}, \mathrm{CH}=\mathrm{CH}_{2}\right), 117.3\left(\mathrm{~s}, \mathrm{CH}=\mathrm{CH}_{2}\right), 66.7(\mathrm{~s}, \mathrm{CH}), 58.2(\mathrm{~s}$, $\left.\mathrm{CH}_{2}\right), 53.9\left(\mathrm{~s}, \mathrm{CH}_{2}\right), 30.6\left(\mathrm{~s}, \mathrm{CH}_{2}\right), 24.2\left(\mathrm{~s}, \mathrm{CH}_{2}\right)$. HR-MS (LC-ESI): calculated for $\mathrm{C}_{8} \mathrm{H}_{15} \mathrm{ON}_{2}[\mathrm{M}+\mathrm{H}]^{+}$ $(\mathrm{m} / \mathrm{z}): 155.1$; found 155.2 .

(S)-(1-Allylpyrrolidine-2-yl)methanamine (15). The synthesis followed the same procedure as described in the literature [12]. The reaction of (S)-1-Allylpyrrolidine-2-carboxamide 14 (2.57 g, $16.67 \mathrm{mmol}$ ) with DIBAL-solution (100 mL, $1 \mathrm{M}$ in THF, 6.0 eq.) gave compound 15 (1.68 g, 11.98 mmol, 72\%) as slightly yellowish oil. ${ }^{1} \mathrm{H}-\mathrm{NMR}\left(400.13 \mathrm{MHz}, \mathrm{CDCl}_{3}\right): \delta(\mathrm{ppm})=5.71-5.57(\mathrm{~m}, 1 \mathrm{H}$, $\left.\mathrm{CH}=\mathrm{CH}_{2}\right), 4.98-4.80\left(\mathrm{~m}, 2 \mathrm{H}, \mathrm{CH}=\mathrm{CH}_{2}\right), 3.16\left(\mathrm{dd},{ }^{2} J_{1}\left({ }^{1} \mathrm{H}_{-}{ }^{1} \mathrm{H}\right)=13.4 \mathrm{~Hz},{ }^{3} J\left({ }^{1} \mathrm{H}^{1} \mathrm{H}\right)=5.5 \mathrm{~Hz}, 1 \mathrm{H}\right.$, $\left.\mathrm{NH}_{2} \mathrm{CH}-\mathrm{H}\right), 2.86-2.79(\mathrm{~m}, 1 \mathrm{H}, \mathrm{CH}), 2.60\left(\mathrm{dd},{ }^{2} J\left({ }^{1} \mathrm{H}-{ }^{1} \mathrm{H}\right)=13.5 \mathrm{~Hz},{ }^{3} J\left({ }^{1} \mathrm{H}-{ }^{1} \mathrm{H}\right)=7.5 \mathrm{~Hz}, 1 \mathrm{H}\right.$, $\left.\mathrm{NH}_{2} \mathrm{CH}-\mathrm{H}\right), 2.48-2.42\left(\mathrm{~m}, 2 \mathrm{H}, \mathrm{CH}_{2}\right), 2.22-1.92\left(\mathrm{~m}, 2 \mathrm{H}, \mathrm{NH}_{2}\right), 1.69-1.41\left(\mathrm{~m}, 6 \mathrm{H}, \mathrm{CH}_{2} \mathrm{CH}_{2} \mathrm{CH}_{2}\right)$. ${ }^{13} \mathrm{C}\left[{ }^{1} \mathrm{H}\right]-\mathrm{NMR}\left(100.63 \mathrm{MHz}, \mathrm{CDCl}_{3}\right): \delta(\mathrm{ppm})=136.1\left(\mathrm{~s}, \mathrm{CH}=\mathrm{CH}_{2}\right), 116.2\left(\mathrm{~s}, \mathrm{CH}=\mathrm{CH}_{2}\right), 65.1(\mathrm{~s}, \mathrm{CH})$, $57.5\left(\mathrm{~s}, \mathrm{CH}_{2}\right), 54.1\left(\mathrm{~s}, \mathrm{CH}_{2}\right), 44.2\left(\mathrm{~s}, \mathrm{CH}_{2} \mathrm{NH}_{2}\right), 27.9\left(\mathrm{~s}, \mathrm{CH}_{2}\right), 22.6\left(\mathrm{~s}, \mathrm{CH}_{2}\right)$.

(S)-N-((1-Allylpyrrolidine-2-yl)methyl)-5-(di-tert-butylfluorosilyl)-2-methoxybenzamide (SiFA-DMFP 4a). To an ice-cooled solution in dry $\mathrm{CHCl}_{3}$ containing the substituted benzoic acid 12a $(0.97 \mathrm{~g}$, $3.10 \mathrm{mmol})$, (S)-(1-Allylpyrrolidine-2-yl)methanamine 15 (0.43 g, $3.10 \mathrm{mmol}, 1.0$ equiv.) and pyridine (0.25 mL, $3.10 \mathrm{mmol}, 1.0$ equiv.) dicyclohexylcarbodiimide (0.64 g, $3.10 \mathrm{mmol}, 1.0$ equiv.) and $N$-hydroxysuccinimide $(0.36 \mathrm{~g}, 3.10 \mathrm{mmol}, 1.0$ equiv. $)$ were added under stirring. The mixture was stirred at $0{ }^{\circ} \mathrm{C}$ for $5 \mathrm{~h}$ and $17 \mathrm{~h}$ at ambient temperature. After the white precipitate had been filtered, the filtrate was washed with saturated $\mathrm{NaHCO}_{3}$-solution $(20 \mathrm{~mL})$ and subsequently with $\mathrm{H}_{2} \mathrm{O}(20 \mathrm{~mL})$. After extracting the aqueous phase with diethyl ether $(20 \mathrm{~mL})$ the combined organic layers were dried with $\mathrm{MgSO}_{4}$, filtered and the solvent was evaporated to give an oily residue. The latter was purified by column chromatography $\left(\mathrm{CHCl}_{3} /\right.$ Ethanol $=20 / 1 \rightarrow \mathrm{CHCl}_{3} /$ Ethanol $\left.=10 / 1\right)$ to afford benzamide $4 \mathbf{a}$ (0.55 g, $1.27 \mathrm{mmol}, 41 \%)$ as a yellowish oil. ${ }^{1} \mathrm{H}-\mathrm{NMR}\left(400.13 \mathrm{MHz}, \mathrm{CDCl}_{3}\right): \delta(\mathrm{ppm})=8.44(\mathrm{~d}$, $\left.{ }^{4} J\left({ }^{1} \mathrm{H}-{ }^{1} \mathrm{H}\right)=1.4 \mathrm{~Hz}, 1 \mathrm{H}, \mathrm{C}(6) \mathrm{H}\right), 8.37\left(\mathrm{~d},{ }^{3} J\left({ }^{1} \mathrm{H}-{ }^{1} \mathrm{H}\right)=3.8 \mathrm{~Hz}, 1 \mathrm{H}, \mathrm{NH}\right), 7.68\left(\mathrm{dd},{ }^{3} J\left({ }^{1} \mathrm{H}-{ }^{1} \mathrm{H}\right)=8.2 \mathrm{~Hz}\right.$, $\left.{ }^{4} J\left({ }^{1} \mathrm{H}-{ }^{1} \mathrm{H}\right)=1.3 \mathrm{~Hz}, 1 \mathrm{H}, \mathrm{C}(4) \mathrm{H}\right), 7.00\left(\mathrm{~d},{ }^{3} J\left({ }^{1} \mathrm{H}-{ }^{1} \mathrm{H}\right)=8.2 \mathrm{~Hz}, 1 \mathrm{H}, \mathrm{C}(3) \mathrm{H}\right), 5.96-5.84\left(\mathrm{~m}, 1 \mathrm{H}, \mathrm{CH}=\mathrm{CH}_{2}\right)$, 5.24-5.06 (m, 2H, CH=CH$), 3.95\left(\mathrm{~s}, 3 \mathrm{H}, \mathrm{OCH}_{3}\right), 3.75\left(\mathrm{ddd},{ }^{2} J\left({ }^{1} \mathrm{H}-{ }^{1} \mathrm{H}\right)=13.8 \mathrm{~Hz},{ }^{3} J\left({ }^{1} \mathrm{H}-{ }^{1} \mathrm{H}\right)=7.1 \mathrm{~Hz}\right.$, $\left.{ }^{3} J\left({ }^{1} \mathrm{H}-{ }^{1} \mathrm{H}\right)=3.1 \mathrm{~Hz}, 1 \mathrm{H}, \mathrm{NHCH}-\mathrm{H}\right), 3.48\left(\mathrm{dd},{ }^{2} J\left({ }^{1} \mathrm{H}-{ }^{1} \mathrm{H}\right)=13.5 \mathrm{~Hz},{ }^{3} J\left({ }^{1} \mathrm{H}-{ }^{1} \mathrm{H}\right)=5.3 \mathrm{~Hz}, 1 \mathrm{H}\right.$, $\left.\mathrm{CH}_{2}=\mathrm{CHCH}-\mathrm{H}\right), 3.35\left(\mathrm{ddd},{ }^{2} J\left({ }^{1} \mathrm{H}-{ }^{1} \mathrm{H}\right)=13.9 \mathrm{~Hz},{ }^{3} J\left({ }^{1} \mathrm{H}-{ }^{1} \mathrm{H}\right)=3.7 \mathrm{~Hz},{ }^{3} J\left({ }^{1} \mathrm{H}-{ }^{1} \mathrm{H}\right)=3.7 \mathrm{~Hz}, 1 \mathrm{H}, \mathrm{NHCH}-\mathrm{H}\right)$, $3.19-3.13(\mathrm{~m}, 1 \mathrm{H}, \mathrm{NCH}-\mathrm{H}), 2.91\left(\mathrm{dd},{ }^{2} J\left({ }^{1} \mathrm{H}-{ }^{1} \mathrm{H}\right)=13.5 \mathrm{~Hz},{ }^{3} J\left({ }^{1} \mathrm{H}-{ }^{1} \mathrm{H}\right)=7.5 \mathrm{~Hz}, 1 \mathrm{H}, \mathrm{CH}_{2}=\mathrm{CHCH}-\mathrm{H}\right)$, $2.75(\mathrm{~s}, 1 \mathrm{H}, \mathrm{CH}), 2.33-2.22(\mathrm{~m}, 1 \mathrm{H}, \mathrm{NCH}-\mathrm{H}), 1.99-1.85\left(\mathrm{~m}, 1 \mathrm{H}, \mathrm{CH}_{2} \mathrm{CH}_{2} \mathrm{CH}_{2}\right), 1.79-1.61(\mathrm{~m}, 3 \mathrm{H}$, 
$\left.\mathrm{CHCH}_{2} \mathrm{CH}-\mathrm{H}\right), 1.02\left(\mathrm{~s}, 18 \mathrm{H}, \mathrm{CCH}_{3}\right) .{ }^{13} \mathrm{C}\left[{ }^{1} \mathrm{H}\right]-\mathrm{NMR}\left(100.63 \mathrm{MHz}, \mathrm{CDCl}_{3}\right): \delta(\mathrm{ppm})=165.5(\mathrm{~s}$, $\mathrm{CONH}), 158.7(\mathrm{~s}, \mathrm{C}(2)), 138.6\left(\mathrm{~d},{ }^{3} J\left({ }^{13} \mathrm{C}-{ }^{19} \mathrm{~F}\right)=3.8 \mathrm{~Hz}, \mathrm{C}(4)\right), 137.7\left(\mathrm{~d},{ }^{3} J\left({ }^{13} \mathrm{C}-{ }^{19} \mathrm{~F}\right)=4.7 \mathrm{~Hz}, \mathrm{C}(6)\right)$, $135.8\left(\mathrm{~s}, \mathrm{CH}=\mathrm{CH}_{2}\right), 125.3\left(\mathrm{~d},{ }^{2} J\left({ }^{13} \mathrm{C}-{ }^{19} \mathrm{~F}\right)=14.5 \mathrm{~Hz}, \mathrm{C}(5)\right), 120.9(\mathrm{~s}, \mathrm{C}(1)), 116.2\left(\mathrm{~s}, \mathrm{CH}=\mathrm{CH}_{2}\right), 110.7$ (s, $\mathrm{C}(3)), 61.9(\mathrm{~s}, \mathrm{CH}), 57.0\left(\mathrm{~s}, \mathrm{CH}_{2} \mathrm{CH}=\mathrm{CH}_{2}\right), 55.5\left(\mathrm{~s}, \mathrm{OCH}_{3}\right), 54.2\left(\mathrm{~s}, \mathrm{NCH}_{2}\right), 41.3\left(\mathrm{~s}, \mathrm{CH}_{2} \mathrm{NH}\right), 28.5$ $\left(\mathrm{s}, \mathrm{CH}_{2}\right), 27.3\left(\mathrm{~s}, \mathrm{CCH}_{3}\right), 22.9\left(\mathrm{~s}, \mathrm{CH}_{2}\right), 20.2\left(\mathrm{~d},{ }^{2} J\left({ }^{13} \mathrm{C}-{ }^{19} \mathrm{~F}\right)=12.0 \mathrm{~Hz}, \mathrm{C}\left(\mathrm{CH}_{3}\right)_{3}\right) .{ }^{19} \mathrm{~F}-\mathrm{NMR}(282.38 \mathrm{MHz}$, $\left.\mathrm{CDCl}_{3}\right): \delta(\mathrm{ppm})=-188.8\left(\mathrm{~s},{ }^{1} J\left({ }^{19} \mathrm{~F}_{-}{ }^{29} \mathrm{Si}\right)=298 \mathrm{~Hz}\right) .{ }^{29} \mathrm{Si}-\mathrm{NMR}\left(59.63 \mathrm{MHz}, \mathrm{CDCl}_{3}\right): \delta(\mathrm{ppm})=14.4$ $\left(\mathrm{d},{ }^{1} J\left({ }^{29} \mathrm{Si}^{19}{ }^{19} \mathrm{~F}\right)=298 \mathrm{~Hz}\right)$. Elemental analysis calculated $(\%)$ for $\mathrm{C}_{24} \mathrm{H}_{39} \mathrm{FN}_{2} \mathrm{O}_{2} \mathrm{Si} \cdot \mathrm{H}_{2} \mathrm{O}(452.68 \mathrm{~g} / \mathrm{mol})$ : C 63.7, H 9.1, N 6.2; found: C 64.1, H 9.1, N 6.3. HR-MS (LC-ESI): calculated for $\mathrm{C}_{24} \mathrm{H}_{40} \mathrm{O}_{2} \mathrm{~N}_{2} \mathrm{FSi}$ $[\mathrm{M}+\mathrm{H}]^{+}(\mathrm{m} / \mathrm{z})$ : 435.2838; found: 435.2832.

(S)-N-((1-Allylpyrrolidine-2-yl)methyl)-5-(di-tert-butylfluorosilyl)-2,3-dimethoxybenzamide (SiFA-FP, 4b). The procedure was analogous to the synthesis of $4 \mathbf{a}$. The reaction of the benzoic acid derivative 12b (1.47 g, $4.28 \mathrm{mmol}$ ) with (S)-(1-Allylpyrrolidine-2-yl)methanamine $\mathbf{1 5}$ ( $0.60 \mathrm{~g}, 3.10 \mathrm{mmol}, 1.0$ equiv.) gave SiFA-FP 4b $(0.81 \mathrm{~g}, 1.74 \mathrm{mmol}, 41 \%)$ as a yellowish oil. ${ }^{1} \mathrm{H}-\mathrm{NMR}\left(400.13 \mathrm{MHz}, \mathrm{CDCl}_{3}\right)$ : $\delta(\mathrm{ppm})=8.51(\mathrm{~s}, \mathrm{br}, 1 \mathrm{H}, \mathrm{NH}), 7.93(\mathrm{~s}, 1 \mathrm{H}, \mathrm{C}(4) \mathrm{H}), 7.24(\mathrm{~s}, 1 \mathrm{H}, \mathrm{C}(6) \mathrm{H}), 5.99-5.87\left(\mathrm{~m}, 1 \mathrm{H}, \mathrm{CH}=\mathrm{CH}_{2}\right)$, 5.27-5.09 (m, 2H, $\left.\mathrm{CH}=\mathrm{CH}_{2}\right), 3.93\left(\mathrm{~s}, 3 \mathrm{H}, \mathrm{OCH}_{3}\right), 3.90\left(\mathrm{~s}, 3 \mathrm{H}, \mathrm{OCH}_{3}\right), 3.80\left(\mathrm{ddd},{ }^{2} J\left({ }^{1} \mathrm{H}-{ }^{1} \mathrm{H}\right)=13.9 \mathrm{~Hz}\right.$, $\left.{ }^{3} J\left({ }^{1} \mathrm{H}-{ }^{1} \mathrm{H}\right)=6.9 \mathrm{~Hz},{ }^{3} J\left({ }^{1} \mathrm{H}-{ }^{1} \mathrm{H}\right)=3.6 \mathrm{~Hz}, 1 \mathrm{H}, \mathrm{NHCH}-\mathrm{H}\right), 3.54\left(\mathrm{dd},{ }^{2} J\left({ }^{1} \mathrm{H}-{ }^{1} \mathrm{H}\right)=13.5 \mathrm{~Hz},{ }^{3} J\left({ }^{1} \mathrm{H}-{ }^{1} \mathrm{H}\right)=5.3 \mathrm{~Hz}\right.$, $\left.1 \mathrm{H}, \mathrm{CH}_{2}=\mathrm{CHCH}-\mathrm{H}\right), 3.47-3.37(\mathrm{~m}, 1 \mathrm{H}, \mathrm{NHCH}-\mathrm{H}), 3.19-3.13(\mathrm{~m}, 1 \mathrm{H}, \mathrm{NCH}-\mathrm{H}), 2.98$ (dd, $\left.{ }^{2} J\left({ }^{1} \mathrm{H}-{ }^{1} \mathrm{H}\right)=13.2 \mathrm{~Hz},{ }^{3} J\left({ }^{1} \mathrm{H}-{ }^{1} \mathrm{H}\right)=7.6 \mathrm{~Hz}, 1 \mathrm{H}, \mathrm{CH}_{2}=\mathrm{CHCH}-\mathrm{H}\right), 2.86(\mathrm{~s}, 1 \mathrm{H}, \mathrm{CH}), 2.39-2.29(\mathrm{~m}, 1 \mathrm{H}$, $\mathrm{NCH}-\mathrm{H}), 2.03-1.91\left(\mathrm{~m}, 1 \mathrm{H}, \mathrm{CH}_{2} \mathrm{CH}_{2} \mathrm{CH}_{2}\right), 1.87-1.67$ (m, 3H, $\left.\mathrm{CHCH}_{2} \mathrm{CH}-\mathrm{H}\right), 1.05\left(\mathrm{~s}, 18 \mathrm{H}, \mathrm{CCH}_{3}\right)$. ${ }^{13} \mathrm{C}\left[{ }^{1} \mathrm{H}\right]-\mathrm{NMR}\left(100.63 \mathrm{MHz}, \mathrm{CDCl}_{3}\right): \delta(\mathrm{ppm})=165.5(\mathrm{~s}, \mathrm{CONH}), 151.9(\mathrm{~s}, \mathrm{C}(2)), 148.8(\mathrm{~s}, \mathrm{C}(3))$, $134.6\left(\mathrm{~s}, \mathrm{CH}=\mathrm{CH}_{2}\right), 129.4\left(\mathrm{~d},{ }^{2} J\left({ }^{13} \mathrm{C}-{ }^{19} \mathrm{~F}\right)=14.0 \mathrm{~Hz}, \mathrm{C}(5)\right), 128.4\left(\mathrm{~d},{ }^{3} J\left({ }^{13} \mathrm{C}-{ }^{19} \mathrm{~F}\right)=4.7 \mathrm{~Hz}, \mathrm{C}(4)\right), 125.8$ $(\mathrm{s}, \mathrm{C}(1)), 120.3\left(\mathrm{~d},{ }^{3} J\left({ }^{13} \mathrm{C}-{ }^{19} \mathrm{~F}\right)=3.9 \mathrm{~Hz}, \mathrm{C}(6)\right), 117.9\left(\mathrm{~s}, \mathrm{CH}=\mathrm{CH}_{2}\right), 62.2(\mathrm{~s}, \mathrm{CH}), 61.2\left(\mathrm{~s}, \mathrm{OCH}_{3}\right), 57.0$ $\left(\mathrm{s}, \mathrm{CH}_{2} \mathrm{CH}=\mathrm{CH}_{2}\right), 56.0\left(\mathrm{~s}, \mathrm{OCH}_{3}\right), 53.9\left(\mathrm{~s}, \mathrm{NCH}_{2}\right), 41.0\left(\mathrm{~s}, \mathrm{CH}_{2} \mathrm{NH}\right), 28.4\left(\mathrm{~s}, \mathrm{CH}_{2}\right), 27.3\left(\mathrm{~s}, \mathrm{CCH}_{3}\right)$, $22.6\left(\mathrm{~s}, \mathrm{CH}_{2}\right), 20.2\left(\mathrm{~d},{ }^{2} J\left({ }^{13} \mathrm{C}-{ }^{19} \mathrm{~F}\right)=12.2 \mathrm{~Hz}, \mathrm{C}\left(\mathrm{CH}_{3}\right)_{3}\right) .{ }^{19} \mathrm{~F}-\mathrm{NMR}\left(282.38 \mathrm{MHz}, \mathrm{CDCl}_{3}\right)$ : $\delta(\mathrm{ppm})=-188.5\left(\mathrm{~s},{ }^{1} J\left({ }^{19} \mathrm{~F}-{ }^{29} \mathrm{Si}\right)=298 \mathrm{~Hz}\right) .{ }^{29} \mathrm{Si}-\mathrm{NMR}\left(59.63 \mathrm{MHz}, \mathrm{CDCl}_{3}\right): \delta(\mathrm{ppm})=14.2(\mathrm{~d}$, $\left.\left.{ }^{1} \mathrm{~J}^{29} \mathrm{Si}^{19} \mathrm{~F}\right)=299 \mathrm{~Hz}\right)$. Elemental analysis calculated (\%) for $\mathrm{C}_{25} \mathrm{H}_{41} \mathrm{FN}_{2} \mathrm{O}_{3} \mathrm{Si} \cdot \mathrm{H} 2 \mathrm{O}(482.70 \mathrm{~g} / \mathrm{mol}): \mathrm{C}$ 62.2, H 9.0, N 5.8; found (\%): C 61.9, H 8.6, N 4.9. HR-MS (LC-ESI): calculated for $\mathrm{C}_{25} \mathrm{H}_{42} \mathrm{O}_{3} \mathrm{~N}_{2} \mathrm{FSi}$ $[\mathrm{M}+\mathrm{H}]^{+}(\mathrm{m} / \mathrm{z})$ : 465.2943; found: 465.2924 .

(S)-N-((1-Allylpyrrolidine-2-yl)methyl)-4-(di-tert-butylfluorosilyl) benzamide (SiFA-DDMFP, 4c). The procedure was analogous to the synthesis of 4a. The reaction of the benzoic acid derivative 12c [17] (0.50 g, $1.77 \mathrm{mmol})$ with $(S)$-(1-Allylpyrrolidine-2-yl)methanamine 15 (0.25 g, $1.77 \mathrm{mmol}, 1.0$ equiv.) gave SiFA-DDMFP 11c $(0.08 \mathrm{~g}, 0.20 \mathrm{mmol}, 11 \%)$ as a yellowish oil. ${ }^{1} \mathrm{H}-\mathrm{NMR}\left(400.13 \mathrm{MHz}, \mathrm{CDCl}_{3}\right)$ : $\delta(\mathrm{ppm})=7.80\left(\mathrm{~d},{ }^{3} J\left({ }^{1} \mathrm{H}-{ }^{1} \mathrm{H}\right)=7.7 \mathrm{~Hz}, 2 \mathrm{H}, \mathrm{Ho}\right), 7.69\left(\mathrm{~d},{ }^{3} J\left({ }^{1} \mathrm{H}-{ }^{1} \mathrm{H}\right)=8.0 \mathrm{~Hz}, 2 \mathrm{H}, \mathrm{Hm}\right), 7.00(\mathrm{~s}, 1 \mathrm{H}$, NH) 5.99-5.86 (m, $\left.1 \mathrm{H}, \mathrm{CH}=\mathrm{CH}_{2}\right), 5.29-5.12\left(\mathrm{~m}, 2 \mathrm{H}, \mathrm{CH}=\mathrm{CH}_{2}\right), 3.73\left(\mathrm{ddd},{ }^{2} J\left({ }^{1} \mathrm{H}-{ }^{1} \mathrm{H}\right)=13.7 \mathrm{~Hz}\right.$, $\left.{ }^{3} J\left({ }^{1} \mathrm{H}-{ }^{1} \mathrm{H}\right)=7.4 \mathrm{~Hz},{ }^{3} J\left({ }^{1} \mathrm{H}^{-1} \mathrm{H}\right)=3.2 \mathrm{~Hz}, 1 \mathrm{H}, \mathrm{NHCH}-\mathrm{H}\right), 3.50-3.43(\mathrm{~m}, 2 \mathrm{H}), 3.2(\mathrm{~s}, 1 \mathrm{H}), 3.04-2.76(\mathrm{~m}$, 2H), 2.42-2.28 (m, 1H), 1.92-1.90 (m, 1H), 1.64-1.54 (m, 3H), $1.06\left(\mathrm{~s}, 18 \mathrm{H}, \mathrm{CCH}_{3}\right) .{ }^{13} \mathrm{C}\left[{ }^{1} \mathrm{H}\right]-\mathrm{NMR}$ $\left(100.63 \mathrm{MHz}, \mathrm{CDCl}_{3}\right): \delta(\mathrm{ppm})=167.8(\mathrm{~s}, \mathrm{CONH}), 137.9\left(\mathrm{~d},{ }^{2} J\left({ }^{13} \mathrm{C}-{ }^{19} \mathrm{~F}\right)=13.7 \mathrm{~Hz}, \mathrm{Cp}\right), 135.2(\mathrm{~s}, \mathrm{Ci})$, $134.1\left(\mathrm{~d},{ }^{3} J\left({ }^{13} \mathrm{C}-{ }^{19} \mathrm{~F}\right)=4.7 \mathrm{~Hz}, \mathrm{Cm}\right), 134.1\left(\mathrm{~s}, \mathrm{CH}=\mathrm{CH}_{2}\right), 126.0(\mathrm{~s}, \mathrm{Co}), 117.4\left(\mathrm{~s}, \mathrm{CH}=\mathrm{CH}_{2}\right), 62.8(\mathrm{~s}$, $\mathrm{CH}), 57.4\left(\mathrm{~s}, \mathrm{CH}_{2} \mathrm{CH}=\mathrm{CH}_{2}\right), 54.1\left(\mathrm{~s}, \mathrm{NCH}_{2}\right), 40.7\left(\mathrm{~s}, \mathrm{CH}_{2} \mathrm{NH}\right), 28.2\left(\mathrm{~s}, \mathrm{CH}_{2}\right), 27.2\left(\mathrm{~s}, \mathrm{CCH}_{3}\right), 23.1$ (s, $\left.\mathrm{CH}_{2}\right), 20.2\left(\mathrm{~d},{ }^{2} J\left({ }^{13} \mathrm{C}-{ }^{19} \mathrm{~F}\right)=12.3 \mathrm{~Hz}, \mathrm{C}\left(\mathrm{CH}_{3}\right)_{3}\right) .{ }^{19} \mathrm{~F}-\mathrm{NMR}\left(282.38 \mathrm{MHz}, \mathrm{CDCl}_{3}\right): \delta(\mathrm{ppm})=-189.2$ 
$\left(\mathrm{s},{ }^{1} J\left({ }^{19} \mathrm{~F}_{-}{ }^{29} \mathrm{Si}\right)=299 \mathrm{~Hz}\right) .{ }^{29} \mathrm{Si}-\mathrm{NMR}\left(59.63 \mathrm{MHz}, \mathrm{CDCl}_{3}\right): \delta(\mathrm{ppm})=14.0\left(\mathrm{~d},{ }^{1} J\left({ }^{29} \mathrm{Si}^{19}{ }^{19} \mathrm{~F}\right)=299 \mathrm{~Hz}\right)$. Elemental analysis calculated (\%) for $\mathrm{C}_{23} \mathrm{H}_{37} \mathrm{FN}_{2} \mathrm{OSi} \cdot \mathrm{H}_{2} \mathrm{O}+\mathrm{C}_{8} \mathrm{H}_{16} \mathrm{~N}_{2}(562.88 \mathrm{~g} / \mathrm{mol})$ : C 66.2, $\mathrm{H} 9.5, \mathrm{~N}$ 8.4; found (\%): C 66.0, H 9.2, N 8.2. HR-MS (LC-ESI): calculated for $\mathrm{C}_{23} \mathrm{H}_{37} \mathrm{ON}_{2} \mathrm{FSi}[\mathrm{M}+\mathrm{H}]^{+}(\mathrm{m} / z)$ : 405.2732; found: 405.2726.

(S)-N-((1-Allylpyrrolidin-2-yl)methyl)-5-(3-(1-(4-(di-tert-butylfluorosilyl)phenyl)-2,5-dioxopyrrolidin3-ylthio)propyl)-2,3-dimethoxybenzamide (SiFA-M-FP, 5). To a freshly prepared solution of 1-(4-(ditert-butylfluorosilyl)phenyl)-1H-pyrrole-2,5-dione (SiFA-maleimide, [17]) (3 mg, $9 \mu \mathrm{mol}$ ) in phosphate buffer (PB, 0.1 M, pH 6.0) and acetonitrile (1:1) was added a solution of $(S)-N$-((1-allylpyrrolidin-2yl)methyl)-5-(3-mercaptopropyl)-2,3-dimethoxybenzamide (FP-thiol) $(3.4 \mathrm{mg}, 9 \mu \mathrm{mol})$ in acetonitrile $(100 \mu \mathrm{L})$ and the $\mathrm{pH}$ of the solution was adjusted to 7.2 using $\mathrm{PB}(0.1 \mathrm{M}, \mathrm{pH}=7.2,200 \mu \mathrm{L})$. After $10 \mathrm{~min}$, the product was isolated by semi-preparative HPLC applying a gradient of $40 \%-80 \%$ acetonitrile in 10 minutes. The product was obtained as white powder after lyophilization $(3.1 \mathrm{mg}$, $4.4 \mu \mathrm{mol}, 49 \%$ yield). ESI-MS calculated for $[\mathrm{M}+\mathrm{H}]^{+}(\mathrm{m} / \mathrm{z}): 712.35$, found: 712.36 .

\subsection{In Vitro Binding Assay}

Evaluation of the dopamine $\mathrm{D}_{2}$-receptor binding affinity: The substances were dissolved in water or DMSO-water mixtures, respectively, and evaluated according to the $\left[{ }^{3} \mathrm{H}\right]$ spiperone binding protocol published by Malmberg and coworkers [21]. Source of the dopamine- $\mathrm{D}_{2}$-receptors was cell line HEK293 which expresses the $\mathrm{D}_{2}$ receptors stably. The $K_{\mathrm{d}}$-value of $\left[{ }^{3} \mathrm{H}\right]$ spiperone was determined in three saturation experiments $\left(41.0 \pm 6.0 \mathrm{pM}( \pm \mathrm{SEM}), \mathrm{p} K_{\mathrm{d}}: 9.398 \pm 0.067\right)$. All substances were evaluated in 3 independent competition experiments in six concentrations (each in triplicate). The $K_{\mathrm{i}}$-values were calculated from the $\mathrm{IC}_{50}$-values according to Cheng-Prusoff [22] as described in detail in [23].

\subsection{Radiolabeling}

General procedure for the labeling of SiFA-compounds. Aqueous $\left[{ }^{18} \mathrm{~F}\right]$ fluoride $(4000-7500 \mathrm{MBq})$ produced by the ${ }^{18} \mathrm{O}(\mathrm{p}, \mathrm{n}){ }^{18} \mathrm{~F}$ nuclear reaction on an enriched $\left[{ }^{18} \mathrm{O}\right]$ water $(95 \%)$ target was loaded onto a Chromafix $\mathrm{PS}-\mathrm{HCO}_{3}$ cartridge and eluted with a mixture of acetonitrile $(800 \mu \mathrm{L})$, water $(200 \mu \mathrm{L})$, potassium oxalate solution $(1 \mathrm{M}, 10 \mu \mathrm{L})$, and Kryptofix $2.2 .2(12.5 \mathrm{mg})$ (procedure a) or eluted with a mixture of $800 \mu \mathrm{L}$ acetonitrile and $300 \mu \mathrm{L}$ aqueous tetrabutylammonium hydrogen carbonate solution ( $0.075 \mathrm{~mol} / \mathrm{L}, \mathrm{ABX}$, Radeberg, Germany) (procedure b). The solvents were removed by coevaporation to dryness under reduced pressure $(650 \mathrm{mbar})$ using a stream of helium at $90{ }^{\circ} \mathrm{C}$ for $4 \mathrm{~min}$. The drying step was repeated twice with acetonitrile $(0.8 \mathrm{~mL})(3 \mathrm{~min})$ and full vacuum $(\sim 10 \mathrm{mbar})$ was applied in the final drying step (4 min). The dried $\left[{ }^{18} \mathrm{~F}\right] \mathrm{F}$-complex was dissolved in dry acetonitrile, DMF or DMSO, respectively, (500-1000 $\mu \mathrm{L})$ and used as stock solution for labeling. The labeling precursors (1-2 mg) were dissolved in dry acetonitrile, DMF or DMSO, respectively $(1 \mu \mathrm{mol} / \mathrm{mL})$ and aliquots containing 5-10 nmol of these stock solutions $(5-10 \mu \mathrm{L})$ were used for labeling and incubated with $250 \mu \mathrm{L}$ of the ${ }^{18} \mathrm{~F}$ stock solutions. After 5 min reaction time at ambient temperature (without stirring), samples were withdrawn from the reaction mixture and analyzed by analytical HPLC. For purification, the reaction mixture was diluted with $10 \mathrm{~mL}$ HEPES-buffer $(1 \mathrm{M}, \mathrm{pH}=4.0)$ and loaded on a SepPak C-18 light cartridge (Waters, Germany), preconditioned with $5 \mathrm{~mL}$ ethanol and $5 \mathrm{~mL}$ isotonic saline. 
The cartridge was washed with $10 \mathrm{~mL}$ isotonic saline and subsequently eluted with $1 \mathrm{~mL}$ ethanol. After dilution with $9 \mathrm{~mL}$ isotonic saline the radiotracers were measured, analyzed by radio-HPLC and used for plasma stability experiments.

In vitro stability in human plasma. To human plasma $(500 \mu \mathrm{L})$ at $37^{\circ} \mathrm{C}$ were added $10-100 \mathrm{MBq}$ of the injectable solutions. The mixture was incubated at $37{ }^{\circ} \mathrm{C}$. After $90 \mathrm{~min}$, aliquots $(75 \mu \mathrm{L}$, in triplicate) were removed and treated with acetonitrile $(75 \mu \mathrm{L})$. Samples were then stored on ice for $5 \mathrm{~min}$ for complete precipitation of the plasma proteins. The precipitate was removed by centrifugation, and the supernatants were analyzed by radio-HPLC. Radioactivity in precipitate and supernatant was measured.

\section{Conclusions}

Motivated by our recent development of a kit-like radiolabeling strategy for the introduction of

${ }^{18}$ F-fluoride into proteins and target-specific peptides using Silicon-Fluoride-Acceptors (SiFAs) and their application in preclinical studies, we synthesized a series of SiFA-containing fallypride/ desmethoxyfallypride derivatives (Figure 2). Compared to other medium-affinity $\mathrm{D}_{2}$-receptor ligands such as DMFP 2, the compounds showed a reduced affinity to the targeted receptor. However, the affinity is still in the nanomolar range and should therefore be high enough for an in vivo application. The radiochemical synthesis of the potential radiotracers, most notably the synthesis time of only $10 \mathrm{~min}$ and the easy cartridge purification, could be a breakthrough in radiofluorinations of small-molecule radiotracers. However, the potential of these SiFA-radiotracers remains to be shown in ongoing in vitro studies regarding receptor subtype-selectivity as well as Pgp-activity and finally in preclinical in vivo studies.

\section{Acknowledgments}

This research was supported by the German Federal Ministry of Education and Research (Munich Biotech Cluster $\mathrm{m}^{4}$, project PM10) as part of the Leading Edge Cluster Initiative and by the Fonds der Chemischen Industrie.

\section{Conflict of Interest}

The authors declare no conflict of interest.

\section{References and Notes}

1. Rosenthal, M.S.; Bosch, A.L.; Nickles, R.J.; Gatley, S.J. Synthesis and some characteristics of no-carrier added [F-18] fluorotrimethylsilane. Int. J. Appl. Radiat. Is. 1985, 36, 318-319.

2. Walsh, J.C.; Akhoon, K.M.; Satyamurthy, N.; Barrio, J.R.; Phelps, M.E.; Gambhir, S.S.; Toyokuni, T. Application of silicon-fluoride chemistry to fluorine-18 labeling agents for biomolecules: A preliminary note. J. Label. Compd. Rad. 1999, 42, S1-S3. 
3. Schirrmacher, R.; Bradtmöller, G.; Schirrmacher, E.; Thews, O.; Tillmanns, J.; Siessmeier, T.; Buchholz, H.G.; Bartenstein, P.; Wängler, B.; Niemeyer, C.M.; et al. F-18-labeling of peptides by means of an organosilicon-based fluoride acceptor. Angew. Chem. Int. Ed. 2006, 45, 6047-6050.

4. Schirrmacher, E.; Wängler, B.; Cypryk, M.; Bradtmoller, G.; Schäfer, M.; Eisenhut, M.; Jurkschat, K.; Schirrmacher, R. Synthesis of $p$-(di-tert-butyl[(18)f]fluorosilyl)benzaldehyde ([F18]SiFA-A) with high specific activity by isotopic exchange: A convenient Labeling synthon for the F-18-labeling of n-amino-oxy derivatized peptides. Bioconjugate Chem. 2007, 18, 2085-2089.

5. Ametamey, S.M.; Mu, L.J.; Hohne, A.; Schubiger, R.A.; Graham, K.; Cyr, J.E.; Dinkelborg, L.; Stellfeld, T.; Srinivasan, A.; Voigtmann, U.; et al. Silicon-based building blocks for one-step F-18-radiolabeling of peptides for PET imaging. Angew. Chem. Int. Ed. 2008, 47, 4922-4925.

6. Höhne, A.; Mu, L.; Honer, M.; Schubiger, P.A.; Ametamey, S.M.; Graham, K.; Stellfeld, T.; Borkowski, S.; Berndorff, D.; Klar, U.; et al. Synthesis, F-18-labeling, and in vitro and in vivo studies of bombesin peptides modified with silicon-based building blocks. Bioconjugate Chem. 2008, 19, 1871-1879.

7. Wängler, B.; Quandt, G.; Iovkova, L.; Schirrmacher, E.; Wängler, C.; Boening, G.; Hacker, M.; Schmoeckel, M.; Jurkschat, K.; Bartenstein, P.; et al. Kit-like 18F-labeling of proteins: Synthesis of 4-(di-tert-butyl[18F]fluorosilyl)benzenethiol (Si[18F]FA-SH) labeled rat serum albumin for blood pool imaging with PET. Bioconjugate Chem. 2009, 20, 317-321.

8. Rosa-Neto, P.; Wängler, B.; Iovkova, L.; Boening, G.; Reader, A.; Jurkschat, K.; Schirrmacher, E. [18F]SiFA-isothiocyanate: A new highly effective radioactive labeling agent for lysine-containing proteins. Chembiochem 2009, 10, 1321-1324.

9. Tietze, L.F.; Schmuck, K. SiFA azide: A new building block for PET imaging using click chemistry. Synlett 2011, 12, 1697-1700.

10. Szlosek-Pinaud, M.; Schulz, J.; Vimont, D.; Bordenave, T.; James, D.; Escudier, J.M.; Allard, M.; Fouquet, E. Silicon-based chemistry: An original and efficient one-step approach to [(18)F]nucleosides and [(18)F]-oligonucleotides for PET imaging. Chem.-Eur. J. 2011, 17, 3096-3100.

11. Höhne, A.; Yu, L.; Mu, L.J.; Reiher, M.; Voigtmann, U.; Klar, U.; Graham, K.; Schubiger, P.A.; Ametamey, S.M. Organofluorosilanes as model compounds for F-18-labeled silicon-based PET tracers and their hydrolytic stability: Experimental data and theoretical calculations (PET = Positron Emission Tomography). Chem.-Eur. J. 2009, 15, 3736-3743.

12. Mukherjee, J.; Yang, Z.Y.; Das, M.K.; Brown, T. Fluorinated benzamide neuroleptics. 3. Development of (S)- $N$-[(1-allyl-2-pyrrolidinyl)methyl]-5-(3-[F-18] fluoropropyl)-2,3-dimethoxybenzamide as an improved dopamine D-2 receptor tracer. Nucl. Med. Biol. 1995, 22, 283-296.

13. Mukherjee, J.; Yang, Z.Y.; Brown, T.; Roemer, J.; Cooper, M. F-18-desmethoxyfallypride: A fluorine-18 labeled radiotracer with properties similar to carbon-11 raclopride for pet imaging studies of dopamine D-2 receptors. Life Sci. 1996, 59, 669-678.

14. de Paulis, T. The discovery of epidepride and its analogs as high-affinity radioligands for imaging extrastriatal dopamine D(2) receptors in human brain. Curr. Pharm. Des. 2003, 9, 673-96.

15. la Fougère, C.; Pöpperl, G.; Levin, J.; Wängler, B.; Böning, G.; Uebleis, C.; Cumming, P.; Bartenstein, P.; Botzel, K.; Tatsch, K. The value of the dopamine $\mathrm{D}(2 / 3)$ receptor ligand (18)Fdesmethoxyfallypride for the differentiation of idiopathic and nonidiopathic parkinsonian syndromes. J. Nucl. Med. 2010, 51, 581-587. 
16. Fehr, C.; Yakushev, I.; Hohmann, N.; Buchholz, H.G.; Landvogt, C.; Deckers, H.; Eberhardt, A.; Klaager, M.; Smolka, M.N.; Scheurich, A.; et al. Association of low striatal dopamine D-2 receptor availability with nicotine dependence similar to that seen with other drugs of abuse. Am. J. Psychiat. 2008, 165, 507-514.

17. Iovkova, L.; Wängler, B.; Schirrmacher, E.; Schirrmacher, R.; Quandt, G.; Boening, G.; Schurmann, M.; Jurkschat, K. para-Functionalized aryl-di-tert-butylfluorosilanes as potential labeling synthons for F-18 radiopharmaceuticals. Chem.-Eur. J. 2009, 15, 2140-2147.

18. Wängler, C.; Waser, B.; Alke, A.; Iovkova, L.; Buchholz, H.G.; Niedermoser, S.; Jurkschat, K.; Fottner, C.; Bartenstein, P.; Schirrmacher, R.; et al. One-step (18)F-labeling of carbohydrateconjugated octreotate-derivatives containing a silicon-fluoride-acceptor (SiFA): In vitro and in vivo evaluation as tumor imaging agents for positron emission tomography (PET). Bioconjugate Chem. 2010, 21, 2289-2296.

19. Sheldrick, G.M. Phase annealing in shelx-90-Direct methods for larger structures. Acta Crystallogr. A 1990, 46, 467-473.

20. Hain, T. International Tables for Crystallography; Kluwer Academic Publishers: Dordrecht, The Netherlands/Boston, MA, USA/London, UK, 1992.

21. Malmberg, A.; Jerning, E.; Mohell, N. Critical reevaluation of spiperone and benzamide binding to dopamine D-2 receptors: Evidence for identical binding sites. Eur. J. Pharmacol. 1996, 303, 123-128.

22. Cheng, Y.; Prusoff, W.H. Relationship between inhibition constant (K1) and concentration of inhibitor which causes 50 per cent inhibition (I50) of an enzymatic-reaction. Biochem. Pharmacol. 1973, 22, 3099-3108.

23. Wängler, C.; Nada, D.; Hofner, G.; Maschauer, S.; Wängler, B.; Schneider, S.; Schirrmacher, E.; Wanner, K.T.; Schirrmacher, R.; Prante, O. In vitro and initial in vivo evaluation of (68)Galabeled transferrin receptor (TfR) binding peptides as potential carriers for enhanced drug transport into TfR expressing cells. Mol. Imaging Biol. 2011, 13, 332-341.

Sample Availability: Contact the authors.

(C) 2011 by the authors; licensee MDPI, Basel, Switzerland. This article is an open access article distributed under the terms and conditions of the Creative Commons Attribution license (http://creativecommons.org/licenses/by/3.0/). 